$\mathcal{G}_{\text {http://dx.doi.org/10.3765/sp.7.11 }}^{\text {Semantics \& Pragmatics Volume 7, Article 11: 1-61, } 2014}$

\title{
Global positive polarity items and obligatory exhaustivity*
}

\author{
Benjamin Spector \\ Institut Jean Nicod (ENS - EHESS - CNRS) \\ Départment d'Études Cognitives, \\ École Normale Supérieure - PSL Research University
}

Submitted 2013-06-26 / First decision 2013-08-29 / Revision received 2014-02-24 / Accepted 2014-04-30 / Final version received 2014-07-15 / Published 2014-11-25

\begin{abstract}
I argue for a distinction between two types of positive polarity items (PPIs) which has not been recognized so far. While for some PPIs, anti-licensing is a strictly local phenomenon, for other PPIs anti-licensing should be stated as a global condition.

I aim to contribute to a principled explanation for the distribution of a significant subset of global PPIs, by relating it to specific semantic properties of the relevant items. More specifically, I argue that PPIs such as soit ... soit ..., quelques and almost trigger obligatory exhaustivity effects and scalar inferences, and that independently motivated constraints regarding the generation of such inferences can account for their distribution. The paper also briefly addresses the case of other global PPIs, e.g., at least, for which a similar account is not straightforwardly available.
\end{abstract}

Keywords: Positive polarity, exhaustivity, scalar implicatures, presupposition, disjunction

* I thank Emmanuel Chemla, Danièle Godard, François Mouret, Natasha Ivlieva, Oriana Kilbourn-Ceron, Orin Percus, Philippe Schlenker, Yasutada Sudo and Ede Zimmermann for useful discussions and remarks. Let me also thank the audience of the linguistics seminars of the University of Frankfurt, the University of Nantes and the University of Paris 7 (Linglunch seminar). I am particularly grateful to Emmanuel Chemla and Jérôme Sackur for detailed discussions about the statistical analyses reported in the appendix and to Lyn Tieu for a very careful reading of a near-final version of the paper. Let me also thank three anonymous reviewers and the editor (Michael Franke) for their extremely useful comments and advice. The research leading to these results has received funding from the Agence Nationale de la Recherche (grants ANR-10-LABX-0087 IEC and ANR-10-IDEX-0001-02 PSL) and the European Research Council under the European Union's Seventh Framework Programme (FP/2007-2013) / ERC Grant Agreement n. 324115-FRONTSEM (PI: Schlenker).

(C)2014 Benjamin Spector

This is an open-access article distributed under the terms of a Creative Commons Attribution License (http://creativecommons.org/licenses/by/3.o/). 
Benjamin Spector

\section{Introduction}

This paper has two goals. First, it argues for a distinction between two types of positive polarity items (PPIs) which has not been recognized so far. While for some PPIs, anti-licensing is a strictly local phenomenon, as discussed, e.g., in Szabolcsi 2004 (e.g., some, someone, somewhere, already, still, simple disjunction in Hungarian - cf. Szabolcsi 2002 - and in French), for other PPIs anti-licensing should be stated as a global condition (primarily complex disjunctions such as French soit ... soit ... and its counterparts in many languages, almost, French quelques, at least, approximately, ...). That is, the latter type (henceforth global PPIs) consists of PPIs that are anti-licensed if and only if their global syntactic environment satisfies a certain semantic property - roughly, downward-entailingness.

Second, I aim to contribute to a principled explanation for these distributional facts, by linking them to specific semantic properties of the relevant items. Focusing first on French soit ... soit ... (henceforth simply soit_soit), I will show that this item triggers exhaustivity effects that are close to being obligatory (henceforth I will simply use obligatory in order to simplify the presentation, but see footnote 16 for relevant remarks). Specifically, it obligatorily gives rise to an exhaustivity inference when it occurs in an upward-entailing (UE) environment, and it also gives rise to very robust anti-presuppositions and strengthened presuppositions when it occurs, respectively, in the restrictor of a quantifier or in the scope of a negated factive verb. If we posit that soit_soit is licensed only when it gives rise to such effects, we can explain both the interpretative facts and the distributional facts, because independently motivated constraints on the distribution of exhaustivity effects will derive the distributional facts. I will discuss the implications of this proposal for current debates about the status of scalar inferences and related exhaustivity effects. The proposal will then be extended to English almost and French quelques. Finally, items such as at least cannot be treated in the same way. I will argue that the licensing of such modifiers in a given syntactic position is nevertheless related to the availability of scalar inferences associated with the modified element in the very same syntactic position.

The paper is organized as follows. Section 2 provides some relevant background about positive polarity items (PPIs). Section 3 argues that soit_soit (and similar items across languages) is a global PPI in the sense outlined above. Section 4 argues that soit_soit triggers obligatory exhaustivity effects, and that constraints on the distribution of the exhaustivity operator correctly 
predict its syntactic distribution. Section 5 offers an account for the fact that soit_soit is licensed in the restrictor of universal and negative quantifiers and in the scope of negated factive predicates. Section 6 argues that English almost is a global PPI as well, and that its distribution should also be accounted for in terms of obligatory exhaustification. Section 7 briefly discusses other global PPIs and tentatively suggests that their distribution too is related to that of exhaustivity operators.

Most of the distributional data that I report regarding French soit_soit and English almost were tested by means of systematic questionnaires, the results of which I present in an appendix. In the paper itself, I resort to the traditional way of reporting judgments and contrasts, using standard notation (?, ??, *, \#, etc.). These notations have a relative character, i.e., they are used to report contrasts.

\section{Background on PPIs}

\subsection{Core properties of PPIs}

Positive polarity items are usually identified as such by two defining properties: anti-licensing, and rescuing.

(1) a. Anti-licensing: PPIs cannot be interpreted under the immediate scope of a non-embedded sentential negation. That is, (1b) cannot be interpreted as meaning that Mary doesn't speak any foreign languages. When felicitous, (lb) means that there are some foreign languages that Mary does not speak.

b. Mary does not speak some foreign languages.

Negation is said to anti-license PPIs. While every PPI is anti-licensed by negation and other antimorphic operators, ${ }^{1}$ it is usually assumed that some but not all of them are anti-licensed by other downward-entailing (henceforth, DE) operators (cf. below and van der Wouden 1997).

(2) a. Rescuing: if the anti-licenser is itself in the scope of a DE-operator, then the PPI is rescued (cf. Szabolcsi 2004 and the references cited therein), i.e., can be interpreted within the scope of the anti-licenser

1 An operator $O$ is antimorphic if it obeys both De Morgan's laws, i.e., if it validates the following equivalence schemata: $O(p \wedge q) \Leftrightarrow(O p \vee O q)$ and $O(p \vee q) \Leftrightarrow(O p \wedge O q)$ 
(typically, negation). Thus (2b) can be interpreted as equivalent to (2c).

b. If Mary does not speak some foreign languages, she should not travel.

c. If it is not the case that Mary speaks one foreign language or more, she should not travel.

\subsection{Types of PPIs}

It is claimed (van der Wouden 1997) that different classes of PPIs have different types of anti-licensers, just as NPIs differ from each other regarding their precise licensing conditions. For instance, already, still, someone, ..., are assumed to be anti-licensed only by antimorphic or anti-additive operators, but PPIs such as a little, almost, relatively, rather are anti-licensed by all DE operators.

This characterization of the various classes of PPIs is not exactly correct. The restrictor of a universal quantifier is both a DE and an anti-additive context, and yet no PPI is anti-licensed within the restrictor of a universal quantifier. More generally, the restrictor of every quantifier fails to antilicense a PPI, whatever its class. Likewise, the antecedent of conditionals, which, on a classical analysis, defines an anti-additive context (hence a DEcontext), does not anti-license PPIs. These facts are illustrated in (3). ${ }^{2}$

(3) a. Every student who is still sleeping will fail the exam.

b. Every student who has almost finished his homework will pass.

c. Few students who are still sleeping will pass.

d. If John is still sleeping, he will fail.

e. If John has almost finished his homework, he will pass.

\section{The distribution of soit_soit}

\subsection{Local vs. global anti-licensing}

Anti-licensing is widely assumed to be a local phenomenon in the following sense: if the anti-licenser is sufficiently distant from the relevant PPI, then

2 These problematic exceptions have a counterpart in the domain of negative polarity items. Strong NPIs (cf. Zwarts 1998), which are supposed to be licensed in anti-additive contexts, fail to be licensed in the restrictor of a universal quantifier or the antecedent of a conditional. See Gajewski 2008 for an interesting perspective on this problem. 
Global PPIs and obligatory exhaustivity

the PPI is licensed in its scope. For instance, Szabolcsi (2004) points out that in the following sentences, someone and something can be interpreted in situ.

(4) I don't think Mary knows someone here.

(5) It's not possible that Mary ate something.

In recent work (Homer, to appear), Homer investigated in depth the locality requirements for both the licensing of NPIs and the anti-licensing of PPIs. While he found strong evidence that the relevant locality conditions vary depending on the identity of the polarity items, he maintained the view that anti-licensing is generally local in the following sense: any PPI can be interpreted within the scope of a negation that is outside of the smallest finite $\mathrm{CP}$ that hosts the PPI.

However, I will argue that for some PPIs anti-licensing is a purely global phenomenon. That is, these PPIs cannot be interpreted under the scope of negation, however distant the negation is, unless the negation is itself in a DE environment (rescuing). The right generalization for these PPIs is that they are anti-licensed if and only if their global syntactic environment meets a certain semantic condition (roughly, DEness). This class of PPIs, which I will now call global PPIs, includes French quelques (a plural indefinite determiner, not to be confused with singular quelqu'un/quelque chose), at least, almost, and the complex disjunctions soit_soit, ou ...ou ..., the adverb approximativement (approximately), among others. I will first concentrate on the relevant facts in the case of French soit_soit and English almost. PPIs for which anti-licensing is not global will be referred to as local PPIs.

\subsection{Soit_soit vs. ou}

Soit_soit vs. ou constitutes an interesting minimal pair: they have a very similar meaning (that of a disjunction), but while ou is a local PPI, soit_soit is a global PPI. Let me start with ou. Ou is a (very mild) PPI in the sense that a) it does not like to be in the immediate scope of negation (cf. (6b) below), and b) it can be rescued under the scope of negation if the negation itself is in a 
Benjamin Spector

DE-context (cf. (7)). ${ }^{3}$ Furthermore, it is a local PPI, since it can be interpreted under the scope of a negation which is sufficiently far away (cf. (8)). ${ }^{4}$

(6) Anti-licensing

a. Marie a invité Léa ou Jean à dîner.

'Marie invited Lea or Jean for dinner.'

b. ?? Marie n'a pas invité Léa ou Jean à dîner. [Under a narrow-scope interpretation for disjunction]

'Paul did not invite Léa or Jean for dinner.'

(7) Rescuing

a. Si Paul n'avait pas invité Pierre ou Julie à dîner, cela aurait été impoli.

'If Paul had not invited Pierre or Julie for dinner, that would have been rude.'

b. Il est peu probable que Paul n'ait pas invité Pierre ou Julie à dîner. 'It is unlikely that Paul did not invite Pierre or Julie for dinner.' [understood as It is likely that Paul invited either Pierre or Julie for dinner.]

(8) Locality of anti-licensing

Je ne pense pas que Marie ait invité Pierre ou Julie à dîner.

'I don't think that Marie invited Pierre or Julie for dinner.' [understood as I don't believe Pierre invited either one]

Now, like $o u$, soit_soit is anti-licensed by a clause-mate negation, but unlike $o u$, it is anti-licensed by negation even when separated from negation by a CP boundary.

3 Anti-licensing in the case of ou is not perceived as very strong. It has been suggested to me that the deviance of (6b) could be explained in terms of a competition with the $n i \ldots n i \ldots$ construction (roughly equivalent to neither ...nor ...). However, the fact that the sentences in (7) are not perceived as deviant at all would not be predicted by a simple account of this type, since the alternative $n i . . . n i$... construction is still possible in these cases.

4 All the reported judgments are to be understood as excluding cases where the relevant negative sentences are echoïc, e.g., used as replies to the corresponding affirmative sentences. PPIs are known to be acceptable in the scope of negation in such contexts (cf., e.g., Horn 1989, Carston 1996). 
Global PPIs and obligatory exhaustivity

(9) Long-distance anti-licensing:

a. * Je ne pense pas que Jacques ait invité soit Anne soit Paul à dîner. [Under a narrow-scope interpretation for disjunction] 'I don't think that Jacques invited SOIT Anne SOIT PAUL for dinner.'

b. *J'ai emmené Marie au cinéma sans qu'elle ait demandé la permission soit à son père soit à sa mère.

Gloss: 'I have brought Marie to the movie theater without that she have-subjunctive asked permission SOIT from her father SOIT from her mother.'

c. [As opposed to:] J'ai emmené Marie au cinéma sans qu'elle ait demandé la permission à son père ou à sa mère.

Meaning: 'I brought Marie to the movies without her having asked permission from her father or her mother.'

Furthermore, the verb douter ('doubt') anti-licenses soit_soit, but not ou, in its CP complement, as (10) and (11) illustrate: ${ }^{5}$

(10) a. Je doute que Nicolas ait mangé les poires ou les oranges. 'I doubt that Nicolas ate the pears or the oranges.'

b. * Je doute que Nicolas ait mangé soit les pommes soit les bananes. 'I doubt that Nicolas ate SOIT the apples SOIT the bananas.'

a. Je doute qu'il soit utile que Jacques apprenne l'espagnol ou le russe.

'I doubt that it be (subjunctive) useful that Jacques learn (subjunctive) Spanish or Russian.'

b. *Je doute qu'il soit utile que Paul apprenne soit l'allemand soit le russe.

'I doubt that it be (subjunctive) useful that Paul learn (subjunctive) SOIT German SOIT Russian.'

As expected, soit_soit can be interpreted in the scope of a negative element if a higher DE operator is present (rescuing):

(12) [In contrast with (9b)]

Je n’emmène jamais Marie au cinéma sans qu'elle ait demandé la permission soit à son père soit à sa mère.

5 I of course ignore irrelevant wide-scope interpretations. With a first-person subject, a widescope interpretation is usually ruled out pragmatically, as it would suggest that the speaker does not know what it is exactly that she finds doubtful. 
Benjamin Spector

'I never bring Marie to the movies without that she have-subjunctive asked permission SOIT from her father SOIT from her mother.'

(13) [In contrast with (11b)]

(?) Personne ne doute qu'il serait utile que Jean apprenne soit l'anglais soit l'espagnol.

'Nobody doubts that it would be useful that Jean learn (subjunctive) SOIT English SOIT Spanish.'

Taken together, these facts show that soit_soit is a PPI for which antilicensing is, at the very least, less local than it is for other PPIs such as ou or English some. Note, in particular, that in sentences such as (11b), the antilicenser is separated from soit_soit by two CP boundaries. Because there is no clear upper bound as to the distance between the anti-licenser and soit_soit (modulo parsing limitations), it is reasonable to conclude that in the case of soit_soit, anti-licensing is simply not restricted by locality constraints. ${ }^{6}$

On this basis, I conclude that soit_soit is anti-licensed by its anti-licensers no matter how distant they are. In this sense, anti-licensing in the case of soit_soit is global. The flip-flop data discussed in Section 3.4 further buttress this claim.

\subsection{Downward-entailingness is sufficient to anti-license soit_soit}

As mentioned above, the relevant logical properties for the licensing and anti-licensing of polarity items vary across different types of polarity items. In the case of soit_soit, the relevant property seems to be DEness (at least), as opposed to a more restrictive property (such as anti-licensing by anti-morphic operators only). This is illustrated by the following contrasts, which show

6 In all the above cases of long-distance anti-licensing, the anti-licensers (ne pense pas, doute) select CP complements in the subjunctive mood. But there are examples of long-distance anti-licensing without this feature. For instance, when croire is not negated but its subject is a DE indefinite (such as few teachers), its CP complement must be in the indicative mood, and in such a case soit_soit cannot be interpreted as taking scope within the CP-complement of croire:

(i) *Peu de professeurs croient que Jacques a appris soit l'allemand soit l'italien.

'Few professors believe that Jacques has (indicative) learned SOIT German SOIT Italian.'

Unlike all other judgments pertaining to soit_soit reported in this section, this specific judgment was not included in my on-line questionnaire, but was tested informally on several informants. 
Global PPIs and obligatory exhaustivity

that, contrary to ou, soit_soit is anti-licensed not only by negation but also by other DE elements, both within the same clause (cf. (14) and (15)) and across CP boundaries (cf. (16)).

(14) [anti-licensing by an antiadditive, non-antimorphic element]

a. *Aucun étudiant ne parle soit italien soit allemand. 'No student speaks SOIT Italian SOIT German.'

b. Aucun étudiant ne parle espagnol ou anglais. 'No student speaks Spanish or English.'

(15) [anti-licensing by a monotone-decreasing, non-antiadditive element]

a. *Peu de français connaissent soit l'italien soit l'anglais. 'Few French people know SOIT Italian SOIT English.'

b. Peu de français connaissent l'allemand ou l'anglais. 'Few French people know German or English.'

(16) [anti-licensing at a distance by a monotone-decreasing, non-antiadditive element.]

a. *Il est peu probable que le fugitif ait fui soit en Allemagne soit en Italie.

'It is little likely that the fugitive fled SOIT to Germany SOIT to Italy.'

b. Il est peu probable que le fugitif ait fui en Allemagne ou en Italie. 'It is little likely that the fugitive fled to Germany or to Italy.'

\subsection{Operator anti-licensing and environment anti-licensing}

At first sight, the phenomenon of rescuing for PPIs suggests that PPI-antilicensing depends on the semantic properties of the PPI's syntactic global environment, rather than on the mere presence or absence of an anti-licenser c-commanding it. As discussed in Szabolcsi 2004, Jespersen (1909-1949) viewed PPIs as elements that must occur in a positive environment, where the relevant notion of positivity is semantic: being in the scope of two negative elements would count as being in a positive environment, because the two negations cancel each other out.

As appealing as this idea seems to be, Szabolsci (2004) argued against it. One of Szabolcsi's many arguments is that in cases of rescuing, adding a third monotone-decreasing operator does not prevent the PPI from being licensed. However, according to an account à la Jespersen, adding a third negative 
operator should in fact make the whole context negative, and thus render the PPI infelicitous. Based on this and other arguments, Szabolsci concludes that anti-licensing should be viewed as a syntactic relation between certain specific operators (e.g., anti-additive operators) and PPIs; she moreover argued that rescuing itself should be specified as involving a syntactic relation between the rescuer and the complex structure made up of a negation and a PPI in its scope. According to this view, the anti-licensing of PPIs cannot be stated in terms of the global semantic properties of syntactic environments. Importantly, the anti-licensing of soit_soit cannot be captured by a system of the sort Szabolcsi advocates. In particular, while soit_soit is rescued when it is in the scope of two DE-operators, it appears to be anti-licensed when it is under the scope of three consecutive DE-operators. ${ }^{7}$ To illustrate this point, consider the following paradigm.

(17) [ou under the scope of $1 \mathrm{DE}, 2 \mathrm{DE}$ and 3 DE-operators]

a. Je trouve inimaginable d'habiter à Paris ou à New-York. 'I find it inconceivable to live in Paris or in New York.'

b. (?) Je trouve inimaginable de ne pas habiter à Paris ou à New York. 'I find it inconceivable not to live in Paris or in New York.'

c. (?) Je ne trouve pas inimaginable de ne pas habiter à Paris ou à New York. 'I don't find it inconceivable not to live in Paris or in New York.'

(18) [soit_soit under the scope of 1 DE, 2 DE and 3 DE-operators]

a. *Je trouve inimaginable d'habiter soit à Paris soit à New-York. 'I find it inconceivable to live SOIT in Paris SOIT in New York.'

b. (?) Je trouve inimaginable de ne pas habiter soit à Paris soit à New York.

'I find it inconceivable not to live SOIT in Paris SOIT in New York.'

c. "Je ne trouve pas inimaginable de ne pas habiter soit à Paris soit à New York.

'I don't find it inconceivable not to live SOIT in Paris SOIT in New York.'

In the case of ou (cf. (17)), the global monotonicity of the environment doesn't seem to play any role. In my survey, (cf. Section A.4.4 of the appendix), the

7 I thank Vincent Homer for pointing out the relevance of this fact. The distinction between environment-based theories and operator-based theories of polarity item licensing is discussed in depth in Homer (to appear). 
Global PPIs and obligatory exhaustivity

acceptability of ou was not significantly different in the scope of one DEoperator than in the scope of two DE-operators; there was however a tendency for ou to be judged less felicitous in the scope of two or three DE-operators than in the scope of just one DE-operator - it may be that, all else being equal, the relevant sentences are harder to parse when their complexity increases. Something quite different happens for soit_soit. In my survey, the sentences with soit_soit that had one or three DE-operators (cf. (18a) and (18c)) were markedly less acceptable than every other sentence in either (17) or (18), while the sentence with 2 DE-operators (cf. (18b)) received approximately the same rating as its counterpart with ou (cf. (17b)).

This indicates that the monotonicity properties of the global context are what matter in the case of soit_soit: as a first approximation, soit_soit is anti-licensed if its global syntactic environment is monotone-decreasing.

\subsection{Restrictors and negated factive verbs}

The generalization that soit_soit cannot occur in globally DE-environments is not entirely correct. First, soit_soit is fully acceptable in the restrictor of all quantifiers, even when such restrictors define a DE-environment. In this respect, soit_soit is no different from other, already documented PPIs. This is illustrated in (19): ${ }^{8}$

(19) [Chaque étudiant qui a]/[Aucun étudiant qui a]/[Peu d'étudiants qui ont] résolu soit le premier soit le second problème a/ont reçu une bonne note.

'[Every student who has]/[No student who has]/[Few students who have] solved SOIT the first SOIT the second problem has/have received a good grade.'

Second, in certain cases where a presuppositional expression, typically a factive verb, intervenes between a DE-operator and soit_soit, soit_soit is acceptable despite being in a globally DE-environment. ${ }^{9}$ This is illustrated by the following contrast, where a negated factive verb is shown not to antilicense soit_soit ((20a)), while a negated non-factive attitude predicate does $((2 \mathrm{Ob}))$ :

8 These judgments were not tested in the questionnaire whose results I report in the appendix. 9 More precisely, in such cases, soit_soit occurs in a Strawson-DE-environment (cf. von Fintel 1999). 
(20) a. Bien qu'elle soit très informée, Léa ne sait pas que Jacques étudiera soit à Yale soit à Princeton.

'Even though she is very well informed, Lea does not know that Jacques will study SOIT at Yale SOIT at Princeton.'

b. ?? Bien que Jacques soit un étudiant brillant, Anne ne croit pas qu'il étudiera soit à Yale soit à Princeton.

'Even though Jacques is a bright student, Anne does not believe that he will study SOIT at Yale SOIT at Princeton.'

I will address the sources of these apparent exceptions in Section 5.

\subsection{Other complex disjunctions}

Besides soit_soit, there is another complex disjunctive construction in French, in which the simple disjunction ou is doubled (ou ... ou ...). The distribution of this construction seems to be constrained in exactly the same way as that of soit_soit. Many other languages have similar complex disjunctions, and such items across different languages appear to behave in the same way as soit_soit in the relevant respects - namely, they are global PPIs. ${ }^{10}$ This is for instance the case, according to the few native speakers I consulted, for both Italian $o \ldots o \ldots,^{11}$ and for German entweder ...oder ....12

So far, I have shown that the theory of PPIs must take into account the distinction between local and global anti-licensing. Focusing on soit_soit (and similar items in French and other languages), I have shown that this item is anti-licensed if its global environment is DE, unless it occurs in the restrictor of a quantifier or in the scope of a negated factive verb (i.e., a Strawson-DE environment). The next sections aim to explain these distributional facts in terms of an independently motivated constraint that regulates the interpretation of soit_soit.

10 Note however that the English complex disjunction either ... or is not a PPI, and yet it tends to strengthen exclusivity inferences. I leave this issue for future research.

11 Italian sia ... sia ... and sia ...che ..., though etymologically related to French soit_soit, have a different meaning: in simple, unembedded cases, both sia ... sia ... and sia ...che ... lead to a conjunctive interpretation. See Zamparelli 2000.

12 German judgments were collected from a few German-speaking colleagues and from the audience of a talk given at the University of Frankfurt, in which I presented a first version of this work. 
Global PPIs and obligatory exhaustivity

\section{Accounting for the distribution of complex disjunctions: Obligatory exhaustification, presupposition strengthening}

In this section, I point to another interesting property of complex disjunctions: they tend to force exclusivity inferences or more complex exhaustivity effects. Furthermore, they give rise to strengthened presuppositions when they occur in restrictors or in the scope of factive verbs. I will argue that these properties can explain the distributional facts I have just discussed, given independently motivated constraints regarding the distribution of exhaustivity operators. ${ }^{13}$ The ideas developed in this section can be viewed as a development of an intuition present in Mouret 2007. Mouret (2007, pp. 201202) briefly suggests that the fact that soit_soit does not like to be interpreted in the scope of negation could be related to its tendency to trigger more robust exclusivity inferences than ou-because these exclusivity inferences are scalar implicatures which, like all scalar implicatures, are suspended in DE-environments.

I will argue that these inferences arise thanks to the presence of an exhaustivity operator in the logical form of sentences. If this is correct, the relevant exhaustivity effects are not conversational implicatures in Grice's sense. I will therefore not call such effects scalar implicatures but will rather use theoretically more neutral terms, such as scalar inference or exhaustivity effects.

\subsection{Complex disjunctions and exclusivity inferences}

So far, I have shown that the complex disjunction soit_soit is a global PPI while the simple disjunction ou isn't (even though it is a local PPI). Furthermore, soit_soit patterns with a number of complex disjunctions across languages, which suggests that we should look for a principled explanation of this fact. Now, soit_soit and ou differ along another dimension as well: speakers

13 This is certainly reminiscent of Chierchia's (2006) approach to polarity licensing, which derives the distribution of NPIs and free-choice items from the assumption that they are obligatory in the scope of an implicature-computing operator. The general architecture of my proposal is however quite different. How these two approaches can be unified is a topic I leave for further research. See also Nicolae 2012 for an account of PPI licensing that is inspired by Chierchia 2006. Nicolae (2012) does not talk about the distinction between local and global PPIs and, in fact, deals only with local PPIs. 
have quite clear intuitions that soit_soit triggers much stronger exclusivity inferences than ou. ${ }^{14}$

Evidence that soit_soit gives rise to more robust exclusivity inferences than ou in unembedded contexts comes from the contrast between the pair in (21) and the one in (22), where each pair is to be understood as a dialogue (these contrasts were gathered in a separate questionnaire with ten native French speakers, and every single participant perceived every single contrast):

a. Marie ira au cinéma lundi ou mardi.

'Marie will go to the movies on Monday or Tuesday.'

b. Absolument ! Et elle ira même à la fois lundi ET mardi.

'Absolutely! She will even go both days.'

(22) a. Marie ira au cinéma soit lundi soit mardi.

'Marie will go to the movies SOIT on Monday SOIT on Tuesday.'

b. \#Absolument! Et elle ira même à la fois lundi ET mardi.

'Absolutely! She will even go on both days.'

In both (21) and (22), the reply contradicts the exclusivity inference which is normally triggered by disjunction in the first sentence, but at the same time it has to be understood as asserting that the first sentence is true (due to absolument). The fact that such a reply is not infelicitous in the case of (21) is expected, given the standard assumption that the exclusivity inference triggered by disjunction is normally optional. ${ }^{15}$ The fact that the very same reply leads to infelicity in the case of (22) shows that in the case of soit_soit, the exclusivity inference is obligatory.

The following contrast can be used to make the same point:

(23) Quelles langues étrangères parlent-ils ?

'Which foreign languages do they speak?'

14 In several French introductions to propositional logic, soit_soit is used to illustrate exclusive disjunction, as opposed to inclusive disjunction. See for instance Ruyer 1994, p. 40.

15 This is not to deny that, in terms of actual processing, there might be a strong tendency to first derive the inference and then to cancel it. The notion of optionality used here does not pertain to on-line processing, but rather to the fact that a reading without the exclusivity inference exists in principle, without which the reply in (21) would feel contradictory. One can compare this case to cases of disambiguation in favor of a less favored meaning, as in: John went to the bank to get some money. He always buries money near the river. It is plausible that bank is first interpreted in the financial sense, but is then reanalyzed as meaning river shore upon hearing the second sentence. 
Global PPIs and obligatory exhaustivity

a. Marie parle allemand ou anglais. Paul aussi: il parle même les deux.

'Marie speaks German or English. Paul too: he even speaks both.'

b. \#Marie parle soit allemand soit anglais. Paul aussi: il parle même les deux.

'Marie speaks SOIT German SOIT English. Paul too: he even speaks both.'

In both (23a) and (23b), the disjunction in the the elided VP has to be inclusive for the whole reply to be consistent. The contrast between (23a) and (23b) shows again that while ou is fully compatible with an inclusive construal, this is not so in the case of soit_soit.

However, soit_soit cannot be equated to an exclusive disjunction: when soit_soit is in the scope of a universal quantifier, the inferences corresponding to the exclusive reading are no longer obligatorily present. This is illustrated by the fact that there is no sense of deviance whatsoever in the following dialogue.

(24) a. Tous mes étudiants étudient soit l'allemand soit l'anglais. 'Every student of mine studies SOIT German SOIT English.'

b. Absolument! Et certains étudient même les deux.

'Absolutely! And some study even both.'

On the other hand, the following would be deviant as a reply to (24a):

(25) \#Absolument! Et ils étudient même les deux.

'Absolutely! And they study even both.'

These facts suggest the following generalization for soit_soit: soit_soit obligatorily triggers the scalar inferences which are normally optionally triggered by disjunction. This generalization captures the strong tendency for the exclusive reading in a non-embedded context. It also captures the facts presented in (24) and (25). In the case of (24), the relevant alternative for exhaustification is given in $(26):^{16}$

16 One cannot be sure based on these data that the relevant inferences are truly obligatory rather than simply strongly favored. Strikingly, even in contexts where speakers are not supposed to be maximally informative, sentences with soit_soit are, to my ear, false if the exclusive inference turns out to be false. Thus consider the Master Minds game, where one has to identify an ordered list of colors. If I know everything relevant, I could help a player by telling her The first color or the third color is red, and if both the first and third colors 
(26) Tous mes étudiants étudient l'allemand et l'anglais.

'Every student of mine studies German and English.'

On the basis of such an alternative, the expected scalar inference for (24a) is the negation of (26), i.e., It is not the case that every student of mine studies both German and English. Now, this proposition is itself fully compatible with a situation where some students (but not all) study both languages, which explains why (24b) is a felicitous reply: (24b) does not contradict the inference. On the other hand, the predicted scalar inference is not compatible with the proposition expressed in (25), which is thus correctly predicted to be deviant.

In connection with (24a), I should also note that an exclusive construal of soit_soit, though not obligatory (as I have just shown), is nevertheless possible, as illustrated by the fact that the following dialogue is felicitous as well (in a context where it is known that Marie is one my students):

(27) a. Tous mes étudiants étudient soit l'allemand soit l'anglais. 'Every student of mine studies SOIT German SOIT English.'

b. Non! Marie étudie les deux !

'No! Marie studies both!'

This is not unexpected given a theory of exhaustivity inferences where scalar items can retain their strong meaning under the scope of a universal quantifier. As discussed in Chemla \& Spector 2011, such theories include both socalled localist theories of scalar inferences and exhaustivity effects (Chierchia, Fox \& Spector 2012) which assume that exhaustification does not necessarily apply to full speech acts, but can apply to subsconstituents of sentences, and certain versions of globalist, neo-Gricean theories (such as Spector 2003, 2007, van Rooij \& Schulz 2004, Schulz \& van Rooij 2006). In fact, to my ear, the dialogue in (27) would also be felicitous if soit_soit were replaced

turn out to be red, my hint was certainly not false, though possibly misleading. In contrast with this, my intuition is that if I said Soit la première soit la troisième couleur est le rouge, then if both turn out to be red, the player would have grounds to complain that I gave her a false indication (see Fox 2014 for a related argument for the view that exhaustivity effects do not arise as conversational implicatures). In any case, even if the obligatoriness claim were to be weakened, this would not affect the logic of my proposal. The fact that soit_soit is degraded in DE-contexts would still be expected if there is a strong preference (rather than an absolute requirement) for soit_soit to occur in the scope of an exhaustivity operator. But we would simply expect soit_soit to be marginally available there, rather than completely ruled out. We would still expect to find the contrasts we observe. 
Global PPIs and obligatory exhaustivity

by a simple disjunction. However, there seems to be a difference between the simple disjunction ou and soit_soit: in many syntactic environments, local strengthening of disjunction seems to be significantly more available with soit_soit than with ou. For instance, when interpreted in the scope of a necessity modal, ou is not easily interpreted as exclusive, while this is clearly a possibility for soit_soit. ${ }^{17}$ This is illustrated by the following contrast:

(28) a. ?\# Pour cet examen, nous devons faire le premier ou le deuxième problème. En d'autres termes, il nous est interdit de faire les deux. 'For this exam, we must solve the first or the second problem. In other words, we are forbidden from solving both.'

b. Pour cet examen, nous devons faire soit le premier soit le deuxième problème. En d'autres termes, il nous est interdit de faire les deux.

'For this exam, we must solve SOIT the first SOIT the second problem. In other words, we are forbidden from solving both.'

These facts can easily be captured within a theory of exhaustivity effects in which they arise due to the presence of an exhaustivity operator in the LF of the relevant sentences. In the case of soit_soit, I assume that soit_soit occurs obligatorily under the scope of an exhaustivity operator (later this licensing condition will be refined):

(29) Soit_soit must occur in the scope of an exhaustivity operator.

In the context of this paper, the exhaustivity operator exh can be defined as applying to a propositional expression $S$ associated with a set of alternatives $A L T(S)$ (a set of propositions), and as returning the conjunction of $S$ and of the negations of the members of $A L T(S)$ which are not entailed by $S:{ }^{18}$

$$
\llbracket \operatorname{exh}(S) \rrbracket=\lambda w \cdot \llbracket S \rrbracket(w)=1 \wedge(\forall \phi \in A L T(S)(\phi(w)=1 \rightarrow(\llbracket S \rrbracket \subseteq \phi)))
$$

The licensing condition in (29) explains the following set of facts:

17 If ou is heavily stressed, the discourse in (28a) improves significantly.

18 This version of the exhaustivity operator runs into problems when the set of alternatives contains symmetric alternatives (following Fox's 2007b terminology), i.e., alternatives which are not entailed by the prejacent of exh but are such that negating both together contradicts the prejacent. See Spector 2003, van Rooij \& Schulz 2004, Fox 2007a for refined versions of the exhaustivity operator that solve this problem, Sauerland 2004 for a related proposal and Chierchia, Fox \& Spector 2012 for a survey. I adopt the simpler version of the exhaustivity operator for presentational purposes. 
- That in a plain, unembedded context, soit_soit tends to trigger an obligatory exclusivity inference (cf. (22) and (23b)). This follows from the fact that in such a case the exhaustivity operator gives rise to an exclusive reading for disjunction.

- That in universally quantified contexts soit_soit is not necessarily interpreted as exclusive, but nevertheless obligatorily triggers an exhausitivity effect (cf. (24) and (25)). This follows from the fact that if the exhaustivity operator takes matrix scope, and if the only alternative used is the one obtained by replacing soit_soit with a conjunction, the resulting reading is not equivalent to what would arise from an exclusive construal of soit_soit.

- That in universally quantified contexts, and more specifically in the scope of necessity modals, soit_soit can be interpreted as exclusive (cf. (27) and (28b)). This follows from the fact that the exhaustivity operator can also be inserted under the scope of a universal quantifier. ${ }^{19}$

\subsection{Constraint regulating the distribution of exh}

A well-known observation (since at least Horn 1972, Fauconnier 1975) is that exhaustive readings cannot normally arise when the relevant scalar item occurs in a DE context (see also Chierchia, Crain, et al. 2001, Crain 2008 for experimental confirmation of this old observation). In the traditional Gricean approach, this follows directly from the fact that they arise as conversational implicatures, and that scalar implicature computation applies to full speechacts, with the result that embedded exhausitivity effects are impossible in any environment. Furthermore, when the relevant scalar item is the lowest element of its scale, embedding it in a DE-context results in a situation where the relevant alternatives (obtained by replacing the scalar item with one of its scale-mates) are weaker than (i.e., entailed by) the target sentence, with the effect that the scalar item in question cannot trigger a global scalar implicature either.

Within the neo-Gricean framework, the distribution of soit_soit could thus follow from a requirement that any occurrence of soit_soit must trigger

19 As a reviewer noted, this does not provide an explanation for the fact that embedded exhaustivity effects appear to be more accessible with soit_soit than with ou. I don't have any account for this fact. 
an exhaustivity effect and that its only alternative is conjunction. ${ }^{20}$ Such a requirement would indeed ensure that soit_soit cannot be embedded in a globally DE-environment. This is essentially the hypothesis that Mouret (2007) briefly considers.

My proposal is based on the same intuition. ${ }^{21}$ However, as discussed in Chierchia, Fox \& Spector 2012, the very fact that with certain scalar items, exhaustivity effects appear to be obligatory is not expected from a purely Gricean point of view, in which they arise as conversational implicatures, i.e., derive from general principles of conversational rationality. In a case where an implicature is first generated but later turns out to create a contradiction with subsequent discourse, the Gricean approach predicts that a rational interpreter will revise his initial understanding and remove the implicature (so-called cancellation, such as, e.g., (21) above - see also footnote 15). But providing a purely Gricean account of the data reported in (22), or of the more general fact that soit_soit is ruled out if it is in a position in which it cannot trigger an exhaustivity effect, is at the very least not a trivial task. Obligatory conversational implicatures are not expected on the Gricean account. Furthermore, supplementing the Gricean approach with a specification that certain implicatures are obligatory does not seem consistent with the underlying conceptual motivation for the Gricean approach. In contrast with this, my proposal has no problem dealing with both types of cases (ou and soit_soit): the reason why (21) is a coherent discourse is that with ou exhaustification is optional (allowing for reanalysis of the first sentence if it was first understood in the exclusive sense), and the reason why (22) sounds incoherent is

20 It is in fact dubious that conjunction is the only alternative induced by disjunction. Rather, as argued by Sauerland (2004) and Spector (2003), a disjunctive phrase $A$ or $B$ also has $A$ and $B$ as alternatives. Once this assumption is made, we run into the problem of symmetric alternatives mentioned in footnote 18. Again, I ignore this complication for presentational purposes.

21 As noted by a reviewer, it is not entirely true that low scalar items cannot retain their strengthened meaning in DE-contexts, specifically in the scope of negation. They can in certain contexts, if the relevant scalar item is stressed. Such cases have been argued to involve a metalinguistic use of negation (cf. Horn 1985). We thus expect soit_soit to be acceptable under negation with prosodic emphasis on soit_soit, in the type of contexts that allow for embedded exhaustive readings in the scope of negation. Following the reviewer's intuitions for Italian $o \ldots o \ldots$, my impression is that this prediction is borne out. That is, the following seems to me to be possible, especially in an echoïc context (with stress on the first occurrence of soit): Jean ne parle pas SOIT allemand, soit anglais, il parle allemand ET anglais ['Jean does not speak SOIT German soit English, he speaks German AND English']. 
that soit_soit triggers obligatory exhaustification (and so reanalysis is not an option).

Within my framework, the unavailability of embedded exhaustivity in DE-environments has to be accounted for by a constraint regulating the distribution of the exhaustivity operator. Following Chierchia, Fox \& Spector (2012), I adopt the following constraint (see also Fox \& Spector 2008):

(31) Economy Constraint on the distribution of exh: An occurrence of exh in a given sentence $S$ is not licensed if eliminating this occurrence leads to a sentence $S^{\prime}$ such that $S^{\prime}$ entails $S$.

This rules out the occurrence of an exhaustivity operator in a DE-environment, since it would result in a globally weaker meaning than the meaning that would arise without it. Furthermore, applying an exhaustivity operator at the matrix level, and associating it with a low scalar item that is itself embedded in a DE-environment, gives rise to a meaning that is equivalent to the one that would arise without the operator (hence would be entailed by it): as in the standard Gricean approach, the relevant alternatives are now entailed by the target sentence, with the result that no alternative can be negated.

\subsection{Explaining the distribution of soit_soit}

The constraint in (31), together with the constraint that soit_soit be under the scope of an exhaustivity operator ((29)), predicts that soit_soit cannot occur in a globally DE-environment. Specifically, as we will see shortly, when soit_soit occurs in a globally DE-environment, it cannot be in the scope of exh without the sentence violating (31).

Let me briefly show this. Suppose soit_soit occurs in a globally DEenvironment. Then soit_soit occurs within the scope of an odd number of DE-operators. The exhaustivity operator exh either scopes over an even or an odd number of DE-operators. If, on the one hand, it scopes over an odd number of DE-operators (for instance if it is inserted at the topmost level), its prejacent defines a DE-environment for soit_soit with the result that exh is vacuous (because the alternative obtained from the prejacent by replacing soit_soit with a conjunction is weaker than the prejacent). If, on the other hand, exh scopes over an even number of DE-operators, it must fall within the scope of an odd number of DE-operators, and therefore occurs in a DEcontext. But, as discussed above, in such a case the presence of exh weakens the global meaning of the sentence, i.e., the reading that results from its 
Global PPIs and obligatory exhaustivity

presence is entailed by the reading that would have arisen in its absence. Hence (31) is once again violated. ${ }^{22}$

\subsection{Remaining issues: when exhaustification is vacuous yet licensed}

The account I am proposing faces two types of problematic cases. The first one (which is based on a remark by Orin Percus, p.c.) is illustrated by the following sentence:

(32) Soit il pleut, soit il ne pleut pas.

'SOIT it is raining, SOIT it is not raining.'

Crucially, the exclusivity inference triggered by soit_soit is in this case a tautology, as it amounts to 'It is not both raining and not raining'. So applying exh here is vacuous, and thus violates the Economy Constraint, and yet (32) is no worse than its counterpart with a simple disjunction.

A second problem has to do with Hurford Disjunctions, which Chierchia, Fox \& Spector (2012) argue involve vacuous exhaustification of the first disjunct: ${ }^{23}$

(33) John will either solve some of the problems or solve all of the problems.

According to Chierchia, Fox \& Spector (2012), (33) is necessarily parsed as John will either (exh(solve some of the problems)) or solve all of them. But exh in this structure is vacuous.

While I will not provide here a complete solution to these problems, let me suggest a possible approach, which is based on joint, ongoing work with Danny Fox (Fox \& Spector 2008). Following ideas first put forward in Gajewski 2002 and subsequently elaborated upon in Fox \& Hackl 2007, I would like to claim that the notion of logical entailment that is relevant to the Economy Constraint is a non-standard one, which operates on very impoverished logical forms. More specifically, a structure $S$ of the form $[s \ldots \operatorname{exh}(\phi) \ldots]$ will fail to satisfy the Economy Constraint just in case for every structure $S^{\prime}$, noted $\left[s^{\prime} \ldots\right.$ exh $\left.\left(\phi^{\prime}\right) \ldots\right]$, which can be obtained from $S$ by arbitrary and non uniform replacements of non-logical items with other non-logical items

22 This conclusion still holds if we assume a more realistic view of the alternatives for disjunctive structures, in which the alternatives for $A$ or $B$ include not only $A$ and $B$ but also $A$ and $B$, as mentioned in footnote 18 .

23 Thanks to Michael Franke for raising this specific question. 
(allowing for cases where only one occurrence of a repeated item undergoes replacement), $S^{\prime}$ happens to be entailed by what results from eliminating exh in $S^{\prime}$.

If such an approach is adopted, (32) no longer violates the Economy Constraint. The reason is that by replacing the second occurrence of pleut by vente ('being windy'), we get a sentence for which exhaustification is no longer vacuous (and, in fact, strengthens the global meaning of the sentence). Likewise, the relevant parse for (33) is no longer ruled out, because by replacing, say, the second occurrence of problems with some other noun, the exhaustivity operator on the first disjunct stops being vacuous. Of course, to make such an account viable, one must be very careful in determining what counts as a non-logical item, and make sure, in particular, that DE operators count as logical (or at least that DEness is "seen" by the grammar, and that the replacement procedure mentioned above can only replace a DE-operator with another DE-operator). ${ }^{24}$ Let me point out that an account along these lines predicts that (33) cannot be embedded in a DE-context, for in such a case the embedded exhaustivity operator cannot strengthen the overall meaning of the sentence, even if the identity of the non-logical vocabulary is ignored. Quite generally, Hurford Disjunctions are themselves expected to be global PPIs, in the sense that they should not be licensed in DE-contexts. Strikingly, this empirical claim has been recently defended by Gajewski \& Sharvit (2012). ${ }^{25}$

\section{Restrictors and factive intervention}

As noted above, soit_soit is licensed in the restrictors of quantifiers and in the scope of negated factive verbs. In this section I show how my proposal can be extended to account for this.

24 And since it is also necessary to count at least some scalar items as logical, the treatment of a Hurford Disjunction such as John solved some or all of the problems will have to assume a more complex underlying structure in which either the verb solved or the noun problems occurs twice - not an implausible assumption given that such a sentence presumably has a parse involving right-node raising.

25 Gajewski \& Sharvit (2012) however predict no factive intervention effect for Hurford Disjunctions. 
Global PPIs and obligatory exhaustivity

\subsection{Restrictors and scalar implicated presuppositions}

I will argue that the licensing of soit_soit in restrictors is in fact compatible with my general approach. My main empirical claim is that the distribution of soit_soit obeys the following generalization:

(34) Soit_soit is licensed only if it occurs in a position in which a low scalar item can trigger a scalar inference.

Now, it turns out that universal quantifiers do not fully behave like runof-the-mill DE-environments, because a low scalar item occurring in such a restrictor triggers what I will call a scalar implicated presupposition. To see this, consider the following sentence:

(35) Every student of mine who solved either the first or the second problem got a good grade.

Disjunction in (35) is interpreted as inclusive, since the whole sentence is understood to imply that I gave a good grade not only to students who solved just one of the two problems, but also to those who solved both. ${ }^{26}$ This is expected given that disjunction occurs in the restrictor of every, hence in a DE-context. Note, however, that (35) also licenses the following inference:

(36) Some students of mine solved the first or the second problem but not both.

Indeed, if every student of mine who solved the first or the second problem (in the inclusive sense) happened to have solved both problems, I would presumably have said (37) rather than (35):

(37) Every student of mine who solved the first and the second problem got a good grade.

Consider also the following example:

(38) Every student of mine who solved some of the difficult problems got a good grade.

26 This does not in principle exclude the possibility of an exclusive construal. In the above example, given our expectations regarding the relationship between solving problems and getting a good grade, an inclusive construal would be preferred even if the sentence were in fact ambiguous between an inclusive and an exclusive construal. See the discussion below in connection with example (42). 
(38) entails that every student of mine who solved all problems got a good grade, which shows that some is not interpreted as equivalent to some but not all. But (38) triggers the inference that some students of mine solved some but not all of the difficult problems - had I known that every student of mine who solved at least some of the difficult problems in fact had solved them all, I would have rather used the definite description the difficult problems, or maybe all of the difficult problems.

These inferences can be viewed as implicated presuppositions (Sauerland 2008) triggered by the relevant scalar item (disjunction in the case of (35), some in the case of (38)), due to a principle known as Maximize Presupposition (Heim 1991, Sauerland 2008). More specifically, they are expected given the following assumptions:

\section{a. Maximize Presupposition}

(i) Contextual Equivalence (auxiliary definition): two sentences are contextually equivalent if and only if they have the same truth value in every world compatible with the common ground.

(ii) If two sentences $S_{1}$ and $S_{2}$ are alternatives of each other and are contextually equivalent, and if $S_{1}$ 's presuppositions asymmetrically entail $S_{2}$ 's presupposition, then pick $S_{1}$ rather than $S_{2}$.

b. Scalar alternatives are relevant to the application of Maximize Presupposition. ${ }^{27}$

c. Aristotelian quantifiers: Non-existential quantifiers presuppose that their restrictors have a non-empty denotation.

Consider again, e.g., (38). According to (39b), Maximize Presupposition applies to (38) on the assumption that it competes with (40):

(40) Every student of mine who solved all of the difficult problems got a good grade.

Given (39c), (40) presupposes that some students of mine solved all of the difficult problems, while (38) presupposes only that some students of mine

27 The standard cases which motivated Maximize Presupposition in the first place (Heim 1991) involved a competition between a presupposition trigger and a non-presuppositional alternative expression. For instance, the oddness of A prime minister of the United Kingdom is bald is supposed to result from a competition between this sentence and The prime minister of the United Kingdom is bald. 
solved at least some of the problems. Since the presuppositions of (40) entail that of (38), an utterance of (38) cannot be felicitous in a context which makes it equivalent to (40) (by (39a)). But if the context entailed that no student of mine solved some but not all of the difficult problems, then (38) and (40) would be contextually equivalent (since in such a case both restrictors would have the same denotation in every world of the common ground). An utterance of (38) is thus felicitous only in contexts which do not entail that no student of mine solved some but not all of the difficult problems. In other words, (38) triggers the implicated presupposition that possibly some students of mine solved some but not all of the problems. This anti-presupposition can in some contexts be strengthened into 'some students of mine solved some but not all of the problems', if for instance it is assumed that I know which problems my students solved (see Chemla 2008 for an explicit account of this strengthening process). By similar reasoning, one derives that (35) triggers the implicated presupposition that possibly some students of mine solved the first or the second problem but not both (which can be strengthened into the presupposition that some students of mine solved the first or the second problem but not both).

Going back to soit_soit, I can now explain the fact that it is felicitous in the restrictors of quantifiers by relating it to the existence of these implicated presuppositions - presuppositions of the form Common Knowledge does not entail that $\phi$, i.e., possibly $\neg \phi$. The principle regulating the distribution of soit_soit should now be stated in the following way: ${ }^{28}$

(41) Soit_soit is felicitous only if it is under the scope of an exhaustivity operator or gives rise to a scalar implicated presupposition.

At this point, let me note that this treatment of strengthened presuppositions triggered by scalar items in restrictors gives rise to a theoretical complication. Namely, the restrictors of universal and negative quantifiers no longer qualify as monotone-decreasing environments. More specifically, the restrictor of a universal or a negative quantifier now defines a Strawson-decreasing environment, but not a decreasing-environment. Informally, this means that

28 It is possible to formally define an alternative-sensitive Maximize Presupposition-operator which adds to its prejacent its implicated presuppositions. As discussed in Singh 2011, Percus (2006) provides evidence that Maximize Presupposition must be able to apply locally, which may motivate the introduction of such an operator. The licensing condition in (41) could then be reformulated to say that soit_soit is licensed only under the scope of exh or that of the Maximize Presupposition-operator. 
such environments are monotone-decreasing relative to the assertive content, but not monotone-decreasing once presuppositions are taken into account. ${ }^{29}$ This has an important consequence: unless I modify the Economy Constraint, I now predict exh to be able to occur within the restrictor of such quantifiers, and, more generally, within Strawson-decreasing environments which are not strictly decreasing. This is so because an embedded exh in such cases weakens the assertive content of the sentence, but at the same time strengthens the non-vacuity presupposition associated with restrictors, as illustrated in (42):

(42) Every student who ${ }_{i} \operatorname{exh}\left(\mathrm{t}_{i}\right.$ solved the first or the second problem) got a good grade.

$m$ Asserts that every student who solved just one of the two problems got a good grade, with no implication regarding those who solved both (assertion is weakened by the presence of exh).

$m$ Presupposes that there is at least one student who solved the first or the second problem but not both (presupposition is strengthened by the presence of $e x h$ ).

The important point is that a sentence such as (42) fails to be entailed, in the strict sense, by the proposition that would be expressed if exh were absent. For in worlds in which no student solved just one of the two problems but every student who solved both problems got a good grade, the variant without exh is true while (42) is neither true nor false. Hence, (42) meets the condition stated in (31). Is the prediction that (42) is licensed correct? In other terms, are embedded exhaustive readings possible in restrictors of negative and universal quantifiers? Such a possibility seems to be at odds with the standard view that embedded exhaustification is generally impossible in DE contexts. However, some of the recent literature argues that embedded exhaustification is possible in the restrictors of universal quantifiers (see in particular Crnič 2013). ${ }^{30}$

29 More formally, a function $f$ from propositions to propositions is Strawson-decreasing if the following holds: for any two (bivalent) propositions $\phi$ and $\psi$ such that $\phi$ entails $\psi$, for every world $w$ such that both $f(\phi)(w) \neq \#$ and $f(\psi)(w) \neq \#$, if $f(\psi)(w)=1$, then $f(\phi)(w)=1$. This definition can easily be generalized to functions applying to the denotations of expressions which have a non-propositional type ending in $t$.

30 I do not discuss if-clauses, which seem to license embedded exhaustification quite easily (cf. Levinson 2000). Since if-clauses can be viewed as restrictors of universal quantifiers over possible worlds, the approach discussed here can be straightforwardly extended to them. 
Global PPIs and obligatory exhaustivity

While this somewhat unconventional prediction should be tested by experimental methods (something which, to my knowledge, has not been done), I do not want to commit myself to the claim that such embedded exhaustivity effects are readily available. It is possible to modify the Economy Constraint so as to rule out exh in all Strawson-decreasing environments, but the choice between the various conceivable versions of the Economy Constraint is not a major concern of this paper as long as it does not affect the predictions regarding the distribution of global PPIs. ${ }^{31}$ What is important from the point of view of this paper is the fact that sentences like (35) clearly trigger scalar implicated presuppositions. Given the generalization proposed in (41), this is sufficient to account for the acceptability of soit_soit in such environments.

\subsection{Factive intervention}

As noted above, factive verbs are able to rescue soit_soit under the scope of negation:

(43) a. *Jacques n'est pas certain que Marie étudie soit l'italien soit l'anglais. 'Jacques is not sure that Marie studies soit Italian soit English.'

b. (ok) Jacques ne sait pas que Marie étudie soit l'italien soit l'anglais. 'Jacques does not know that Marie studies SOIT Italian SOIT English.'

This contrast is again expected given my approach, because, as has been observed by Gajewski \& Sharvit (2012), when the CP complement of a negated

31 To rule out structures such as (42), one option is to strengthen the condition regulating the distribution of exh stated in (31). Instead of requiring only that an occurrence of exh does not weaken the meaning of the sentence (i.e., does not make the sentence entailed by its variant without the occurrence of exh), one might require that an occurrence of exh in a sentence $S$ actually have a strengthening effect (i.e., $S$ should asymmetrically entail the reading that would result if exh were absent). Such a constraint would rule out exh not only in monotone decreasing environments, but also in non-monotonic ones. In fact, the restrictor of a universal quantifier, given the non-vacuity presupposition associated with it, turns out to be non-monotonic in the strict sense. This consequence might be problematic in light of experimental evidence that embedded exhaustive readings are available in at least some non-monotonic contexts (cf. Chemla \& Spector 2011, but see also Geurts \& van Tiel 2013 for a criticism of Chemla \& Spector's conclusions). A possible refinement could consist of distinguishing contexts which are non-monotonic due to their assertive content alone and contexts which are non-monotonic in the strict sense but nevertheless Strawson-decreasing (von Fintel 1999). Some aspects of the behavior of almost, discussed in Section 6.3, are relevant to this issue. 
factive verb contains a low scalar item, the resulting presupposition that the embedded clause is true tends to be enriched with the scalar inference that the clause would trigger in isolation:

(44) Mary doesn't know that Peter solved the first or the second problem. m Peter solved one of the two problems but not both.

Since a low scalar item in such a configuration can trigger a scalar inference, we expect soit_soit to be possible in such a configuration, and to obligatorily trigger the corresponding scalar inference. And it is indeed the case that (43b) is perceived as entailing that Marie studies either Italian or English but not both.

While the phenomenon of presupposition strengthening observed in connection with (44) is reminiscent of that of implicated presuppositions discussed in Section 5.1, it turns out, on closer examination, that it cannot be derived by the same mechanism. More specifically, the consequences of the Maximize Presupposition principle are too weak to ensure that (44) is necessarily infelicitous if in fact it is common knowledge that Peter solved both the first and the second problem. Let us see why.

Assume that (44) has been uttered. What Maximize Presupposition tells us is that (44) cannot be contextually equivalent to its competitor in (45) (since (45)'s presuppositions logically entail those of (44) - cf. (39)).

(45) Mary doesn't know that Peter solved both the first and the second problems.

What I am going to show is that there exists a context where a) it is common knowledge between the participants of the conversation that Peter solved both the first and the second problem, and b) nevertheless (44) and (45) are not contextually equivalent. In such a context (44) can be uttered without there being any violation of Maximize Presupposition. This is sufficient to show that Maximize Presupposition does not by itself predict (44) to be infelicitous if common knowledge entails that Peter solved both problems. Here is a characterization of such a hypothetical context. First, it is a context where Mary is not herself a participant of the conversational exchange (i.e., her beliefs play no role in determining the common ground). Second, the set of worlds compatible with the common ground (i.e., what is common knowledge between the participants of the conversational exchange) have the following two properties: 
Global PPIs and obligatory exhaustivity

i. All the worlds compatible with the common ground are worlds where Peter solved both problems.

ii. These worlds divide into two types: worlds $W 1$ in which Mary knows that Peter solved Problem 1 or Problem 2 but does not know that he solved both, and worlds $W 2$ in which Mary believes (wrongly) that Peter didn't solve any problems at all.

Now, in worlds of type $W 1,(44)$ is false, but (45) is true. In worlds of type $W 2$, both (44) and (45) are true. Hence (44) and (45) are not contextually equivalent in such a context (i.e., they don't have the same truth-value across all the worlds compatible with the common ground), and thus it should be possible for a participant of the conversational exchange to utter (44) without violating Maximize Presupposition (and such an utterance would in fact tell the participants that the actual world is a world of type $W 2$ rather than $W 1$ ). But note that in this context it is common knowledge that Peter solved both problems.

The phenomenon of presupposition strengthening in the case of factive verbs and that of implicated presuppositions thus raise a non-trivial unification problem, which I will not attempt to solve here. The important point is that soit_soit is licensed under the scope of negation precisely in contexts which give rise to presupposition strengthening. Given my specific implementation, what I need to assume in order to make this prediction is that the exhaustivity operator is also responsible for these strengthened presuppositions. One possible way to achieve this is to stipulate that in the case of factive verbs, exh treats the factive presupposition on a par with the asserted content. In the case of (44), the exhaustivity operator would then apply to the proposition expressed in (46a), the alternative of which is given in $(46 b)$.

(46) a. Peter solved the first or the second problem and Mary does not know that Peter solved the first or the second problem.

b. Peter solved the first and the second problem, and Mary does not know that Peter solved the first and the second problem.

Let me represent Peter solved the first problem as $F$, Peter solved the second problem as $S$, and let me use the notation $K \phi$ to express that $\phi$ is true in every world compatible with Mary's knowledge. Applying exh to (44) thus results in the following: 
Now, (47) entails $\neg K(F \vee S)$, which in turn entails $\neg K(F \wedge S)$ (because $K$ is a monotone increasing operator). So the only way in which the second, larger conjunct $(\neg[(F \wedge S) \wedge \neg K(F \wedge S)])$ can be true is if $F \wedge S$ is false. (47) is thus equivalent to (48), which is the desired result:

(48) $\quad(F \vee S) \wedge \neg(F \wedge S) \wedge \neg K(F \vee S)$

$=$ Peter solved the first or the second problem but not both, and Mary does not know that Peter solved the first or the second problem.

\section{Another global PPI: almost}

English almost appears to be a global PPI. It is anti-licensed both by a clausemate negation and by negation across a CP boundary, as the data in (49) and (50) illustrate - all the contrasts reported in this section were tested in an on-line questionnaire, as discussed in the appendix. ${ }^{32}$

(49) [Anti-licensing by a clause-mate negation]

a. Mary solved all of the problems on time.

b. Mary didn't solve all of the problems on time.

c. Mary solved almost all of the problems on time.

d. ?? Mary didn't solve almost all of the problems on time.

(50) [Long-distance anti-licensing]

a. I think that Mary solved all of the problems on time.

b. I don't think that Mary solved all of the problems on time.

c. I think that Mary solved almost all of the problems on time.

d. ?? I don't think that Mary solved almost all of the problems on time.

Almost is also anti-licensed by a DE indefinite such as few:

(51) a. Many countries are close to having full nuclear capacity.

b. Few countries are close to having full nuclear capacity.

c. Many countries almost have full nuclear capacity.

d. ?? Few countries almost have full nuclear capacity.

32 I often use ?? rather than * because the contrasts were a little bit less sharp in the case of almost than in the case of soit_soit. 
While these examples show that almost a) passes the test of long-distance anti-licensing, and b) is anti-licensed in DE contexts quite generally, the following data suggest that, like other PPIs, it can be rescued under the scope of an anti-licenser when this anti-licenser is itself in the scope of a negative element (as reported in the appendix - B.3.2-, this contrast in my survey was quite weak compared to some others, but was statistically significant, and so was the expected interaction between the two relevant factors, i.e., simple vs. double negation and all vs. almost all):

(52) a. I left the party without having told all of the guests that I was leaving.

b. ?? I left the party without having told almost all of the guests that I was leaving.

c. I never leave a party without having told all of the guests that I am leaving.

d. (?) I never leave a party without having told almost all of the guests that I am leaving.

Just like soit_soit, almost is fine in restrictors ((53)), and is also fine in the scope of negation if a factive verb intervenes. The sentences in (54) illustrate that almost is fine under neg+know, but not under neg+think, and that removing almost eliminates the contrast.

(53) Every student who has almost finished will go out tonight.

(54) a. Lisa informed her parents that she did very well at the exam, but they don't know that she solved almost all of the problems.

b. ?? Lisa informed her parents that she did very well at the exam, but they don't think that she solved almost all of the problems.

c. Lisa informed her parents that she did very well at the exam, but they don't know that she solved all of the problems.

d. Lisa informed her parents that she did very well at the exam, but they don't think that she solved all of the problems.

In the next section, I will show that almost can receive an analysis which is very similar to the one that has just been developed for soit_soit. Namely, a lot of puzzling facts about the interpretation of almost can be made intelligible by assuming that it is required to occur under the scope of an exhaustivity operator. 
Benjamin Spector

\subsection{Almost and negative implicata}

At first sight, a sentence such as (55) has quite straightforward truth-conditions. It is true if Mary's exact age is close to 18 years old, but strictly less than 18 years old:

(55) Mary is almost 18 years old.

Likewise, (56) implies that Marie has not finished yet, but soon will.

(56) Marie has almost finished.

$\rightsquigarrow$ Marie has not finished.

So almost, as a rule, seems to trigger the following inference (among others):

(57) Almost $\phi \leadsto \neg \phi$

In the literature, this inference has been described as a) obligatory, and b) different from a standard implication (Jayez \& Tovena 2008, Nouwen 2006) in various ways. For instance, as observed in Jayez \& Tovena 2008 for French presque, there is an interesting contrast between the following two dialogues:

(58) a. Is Mary young?

b. Absolutely! She is about to turn seven.

(59) a. Is Mary young?

b. \#Absolutely! She is almost seven.

What this contrast shows is that, even though She is almost seven implies that Mary is younger than 7 years old, this implication cannot be used to argue that Mary is young, in contrast with what we see with She is about to turn seven. This suggests that, in some intuitive sense, this implication is not part of the main point of the utterrance. Jayez \& Tovena (2008) argue, convincingly in my view, that this implication is not a presupposition. ${ }^{33}$

Another striking fact about this inference is that it does not always seem to be attached to the meaning of the relevant sentences when these sentences are embedded. Nouwen (2006), for instance, discusses the following example:

33 Note for instance that sentences with almost fail the wait a minute! test:

(i) a. Mary is almost seven.

b. \#Wait a minute! I didn't know she was not seven yet. 
Global PPIs and obligatory exhaustivity

(6o) If you want to pass the exam, you have to answer almost all questions correctly.

Nouwen notes that (6o) does not mean that if you want to pass the exam, your obligation is to pass almost all but not all of the questions, which would entail that you fail the exam if you solve all questions. Rather, it means that in order to pass, you have to answer at least almost all the questions, and you don't have to answer all of them. Now, in this specific case, one might argue that almost is interpreted as scoping above the modal have (yielding 'You almost have to answer all questions, but you don't have to answer all questions'). But an analysis of this type is not very plausible for the following case:

(61) [Context: On some days, John does not do even half of his homework. On other days, he finishes his homework. Quite often, he does most of his homework, but not all of it. His parents are not terribly demanding, and they sometimes take him to the movies even when he has not completely finished his homework. Nevertheless ....]

They never take him to the movies unless he has almost finished his homework.

The point here is, again, that (61) is not interpreted in this context as implying that John's parents never take him to the movies when he has completely finished his homework. Rather, it means that they never take him to the movies unless he has at least almost finished. While an analysis where almost takes maximal scope may derive the desired reading (thanks to Oriana KilbournCeron for pointing this out to me), such an analysis is hard to motivate from a syntactic point of view, given that other degree operators cannot take maximal scope in the same configuration. For instance, the sentence They never take him to the movies unless he has solved fewer than four problems cannot mean 'the greatest number $n$ such that they never take him to the movies unless he has solved $n$ problems or more is smaller than four' ${ }^{34}$

Based on similar considerations, Sadock (1981) argued that the negative implication triggered by almost is a conversational implicature, akin to a scalar implicature. Penka (2006) and Nouwen (2006) rebut this claim, on the basis of the following argument: if this negative implication were a conversa-

34 In contrast with this, you have to solve fewer than four problems can mean that the number that has to be solved at the minimum is smaller than four, and this reading can be analyzed as involving a wide-scope construal of fewer than four, as discussed in Heim 2000. 
tional implicature, then it should be only optionally present. I concur with this argument, and agree that the observed negative implication cannot be a conversational implicature in Grice's sense. However, within the grammatical approach to scalar inferences, this does not exclude the possibility that the negative implications triggered by almost are an obligatory exhaustivity effect. Obligatory scalar inferences are not expected if scalar inferences are conversational implicatures, but they are not particularly problematic if they arise by means of an exhaustivity operator - since in some cases the presence of the operator could be obligatory.

\subsection{Almost and obligatory exhaustification}

The facts I have just reviewed can be accounted for by assuming that the negative implication triggered by almost is not part of its lexical meaning, but comes about as an obligatory scalar inference, due to a requirement that almost be under the scope of an exhaustivity operator. When almost is sufficiently embedded, there are multiple choices as to the insertion site of the exhaustivity operator. When some other operator intervenes between the exhaustivity operator and almost, the negative implication is computed at the level of the exhaustivity operator, so that the negative implication which is associated with almost $\phi$ in isolation does not necessarily survive when almost $\phi$ is embedded. Let me explain more precisely how such a story could work. To get going, I need to make some specific assumptions about the meaning of almost. ${ }^{35}$

(62) a. Let $\phi$ be a degree predicate. Then almost $\phi(d)$ is true if there is a degree $d^{\prime}$ which is very close to $d$ on the relevant scale such that $\phi\left(d^{\prime}\right)$ (a more formal implementation would have to make use of a contextual parameter in terms of which the relevant notion of closeness would be defined).

b. $\phi(d)$ is an alternative to almost $\phi(d)$.

c. almost $\phi(d)$ has to occur under the scope of an exhaustivity operator which is associated with it (in the sense of association with focus). The alternatives for this exhaustivity operator thus have to be the ones generated by almost $\phi(d)$.

35 These assumptions are clearly too simplistic, if only because almost does not only modify degree predicates. They are sufficient for my purposes. See Nouwen 2006 for a comparison of various proposals for almost, and the literature cited therein. See also Penka 2006. 
Global PPIs and obligatory exhaustivity

Let us start with John is almost 21 years old. I assume that the degree predicate old is downward-monotonic relative to its degree argument, i.e., for any $d, d^{\prime}$ such that $d<d^{\prime}$, being $d^{\prime}$-old entails being $d$-old - one is $d$-old if and only if one's age is $d$ or more. Given (62), John is almost 21 years old must have the following representation:

(63) exh(almost [John is 21 years old])

This is predicted to mean the following:

(64) For some $d$ very close to 21 years, John is $d$-old, and John is not 21 years old.

Given the assumption that old is downard-monotonic relative to its degree argument, we have to choose a $d$ that is strictly smaller than 21 years. For any $d$ equal to or greater than 21 years, (64) would be a contradiction. So the result we get is that John's exact age is smaller than but very close to 21 years, which is clearly correct. ${ }^{36}$

For cases where there is no overt degree expression, as in John has almost finished or the bottle is almost empty, I assume that the relevant predicate (finished or empty) is a degree predicate whose degree argument is filled by the maximal element of its scale, call it max (following Kennedy's (2007) assumption regarding predicates whose scale has an upper bound). ${ }^{37}$ The relevant representation for John has almost finished is thus the following:

(65) exh(almost[John has max-finished])

This is predicted to mean the following, which is, again, an intuitively correct result:

(66) For some $d$ close to $\max$, John has $d$-finished, and it is not the case that John has max-finished.

36 With such a semantics, I also capture Nouwen's (2006) observation that when almost modifies a non-monotonic degree predicate, as in John is almost exactly 21 years old, then there is no implication that John is younger than 21 years old, but only that his age is close to 21 years. My informal proposal captures this fact, whether I assume that almost modifies exactly or exactly 21 years old.

37 It is well known that almost cannot easily modify a degree predicate whose scale does not have an end-point, such as tall. Cf. Kennedy 2007 and Rotstein \& Winter 2004. 
Let us now look at cases where almost occurs under the scope of various operators, as in (67):

(67) You can go to the movies only if you have almost finished your homework.

A possible representation for (67), given my assumptions, is the following:

(68) exh (you can go to the movies only if you have almost finished your homework).

Ignoring the contribution of exh, (68) means that you can go to the movies only if you have at least almost finished your homework. To this exh adds the negation of you can go to the movies only if you have finished your homework. So the resulting meaning has to entail that you don't have to have completely finished your homework in order to go to the movies. This is a correct result: (67) conveys that it is necessary for you to have at least almost finished your homework, but that it is not necessary for you to have completely finished.

The cases discussed by Nouwen work in a completely similar way. Consider for instance (6o), repeated below as (69):

(69) (If you want to pass the exam,) you have to answer almost all questions correctly.

Under the representation given in (70), (69) is predicted to mean that in order to pass the exam, the number of questions you answer correctly has to be very close to the total number of questions, but does not have to be equal to that number. ${ }^{38}$

(70) exh(you have to answer almost all questions correctly).

Looking at cases involving factive intervention, it is interesting to note that the negative implicatum normally triggered by almost tends not to contribute to the asserted content, but only to the factive presupposition itself. Thus consider the following.

(71) Mary does not know that Peter has almost finished.

38 As noted above, my toy semantics for almost does not allow it to modify a non-scalar predicate, and hence cannot handle this case. See Penka 2006 for a more realistic semantics for almost. 
Global PPIs and obligatory exhaustivity

Clearly, (71) triggers the inference that Peter has almost finished but not quite. However, it does not seem to mean that what Mary does not know is the fact that Peter has almost finished but not quite. For suppose that Mary, in fact, erroneously believes that Peter has completely finished, based on some conclusive evidence. Then it is far from clear that (71) can be said to be true. The reading that seems to be the most salient is thus one in which (71) presupposes that Peter has almost finished but not quite, and asserts that Mary does not know that Peter has at least almost finished. This is fully expected within my approach, given the way scalar inferences generally project in such contexts (cf. Section 5.2). ${ }^{39}$

Now, if negation is removed, then the negative implicatum can be part of the content that is attributed to the attitude holder, as in the following example:

(72) Mary knows that Peter has almost finished.

(72) can easily be understood as implying that Mary knows both that Peter is not far from having finished and that he has not yet completely finished. One could for instance object to (72) by saying No! Mary does not know that Peter has not completely finished. On my view, this reading results from the availability of the following structure.

(73) Mary knows that [exh(Peter has almost finished)].

On the other hand, I also predict the possibility of the following structure.

(74) exh[Mary knows that Peter has almost finished].

Given the assumption that factive presuppositions get strengthened by the exhaustivity operator as if they were part of the asserted content, the meaning of (74) is the following:

(75) Mary's knowledge entails that Peter has reached a degree of completion close to the maximal degree, Mary's knowledge does not entail that Peter has completely finished, and in fact Peter has reached a de-

39 Cf. related remarks in Nouwen 2006. This pattern would not be expected if the negative implicatum triggered by almost were a presupposition. Indeed, when a sentence $\phi$ presupposing $p$ is embedded under $X$ (doesn't) know that ..., the resulting sentence normally presupposes that the referent of $X$ knows $p$. For instance, Mary does not know that Peter stopped smoking presupposes that Peter used to smoke and that Mary knows this (but doesn't know that he stopped smoking). 
gree a completion close to the maximal degree but has not completely finished.

While (75) is false if Mary erroneously believes that Peter has completely finished, it is in fact compatible with a situation where Mary knows that Peter is close to having finished and has no opinion as to whether Peter in fact has finished. This reading is therefore weaker than the one corresponding to (73), in that it does not entail that Mary knows that Peter has not completely finished; rather, it only entails that she does not have the belief that Peter has completely finished (which allows for situations where she is simply not sure). The felicity of the following discourse suggests that this weaker reading also exists. ${ }^{40}$

(76) Mary knows that Peter has almost finished, but she doesn't know that he hasn't completely finished.

\subsection{Predicting the distribution of almost}

If, as I assume, almost is specified as necessarily occuring in the scope of an exhaustivity operator, its distribution is straightforwardly explained, in exactly the same way as that of soit_soit is. It cannot occur in pure DE-contexts, because in such a case, applying exh in a position that c-commands almost would either result in a sentence that is strictly weaker than the sentence without exh, or would be vacuous, as explained in Section 4.3. In cases involving factive intervention, as we have just seen, the presence of almost is able to add a negative implicatum to the presupposition of the relevant sentences, which is why it can occur in the scope of an exhaustivity operator without giving rise to a violation of the Economy Constraint. Finally, we have just seen in connection with example (72) that in upward-entailing contexts, there are in principle several possible insertion sites for exh, resulting in rather subtle ambiguities.

What about restrictors? Consider the following example:

(77) All the students who have almost finished their homework will go out tonight.

40 Of course, an objection such as No! Mary does not know that Peter has not completely finished is not expected to be possible under this construal. The fact that this objection is felicitous has to be attributed to the availability of the reading corresponding to (73). 
Similarly to the discussion in Section 5.1, one expects that this sentence can be construed as asserting that all the students who have almost or completely finished their homework will go out tonight, and as triggering the implicated presupposition that there are students of mine who have almost finished their homework without having completely finished. This construal corresponds to the result of applying Maximize Presupposition, which enriches the sentence with a scalar implicated presupposition and thus licenses almost, which is why (77) is not ruled out.

But as I also discussed, depending on how exactly the Economy Constraint is formulated (cf. Section 5.1), I do not necessarily exclude another construal, in which the exhaustivity operator is inserted in the restrictor of the universal quantifier, just above almost. Under this construal, (77) is interpreted as equivalent to All the students who have almost finished their homework but not quite will go out tonight. To the extent that this reading is also available, it provides an argument for the first version of the Economy Constraint ((31)) - rather than the modified version discussed in footnote 31.

\section{Other global PPIs: Class B modifiers}

French includes a number of positive polarity items for which an account along the same lines seems very plausible. For instance, the determiner quelques (approximately a few), and the expression un peu (a little), which can function both as a determiner with mass nouns and as an adverb, display a similar behavior as soit_soit. According to all my informants, they are degraded in globally monotone-decreasing environments and rescued in similar configurations as soit_soit (doubly negative environments, restrictors, negated factive verbs). Furthermore, they both give rise to strong scalar inferences (both quelques and a few trigger a not many inference in unembedded contexts). The proposal I have developed for soit_soit and almost can be extended straightforwardly to such items.

However, there is another class of items which qualify as global PPIs but cannot be treated in the same way as soit_soit, almost, quelques or ou. This class includes modifiers such as at least or approximately, which Nouwen (2010) calls Class B modifiers. I briefly address this class in the subsequent sections. 
Benjamin Spector

\subsection{At least}

At least is generally infelicitous in the immediate scope of negation, suggesting that it is a PPI.

(78) a. ?? Mary didn't solve at least three problems.

b. ?? Mary left without having talked to at least two people.

(Under the intended narrow-scope reading: 'Mary left and she talked to no more than one person')

The following facts illustrate that at least is a global PPI.

- Long-distance anti-licensing

(79) a. ?? Few people believe that Mary is at least 20 years old.

b. ?? John doesn't think Mary is at least 20 years old.

c. ?? Jack bought cigarettes even though he is not at least 18 years old.

As expected, for every sentence in (79), replacing at least with more than removes any feeling of infelicity:

(80) a. Few people believe that Mary is more than 20 years old.

b. John doesn't think Mary is more than 20 years old.

c. Jack bought cigarettes even though he is not more than 18 years old.

Note that At least is bad in DE-environments also when it does not modify a degree expression.

(81) a. ?? Few people think that Mary saw at least Peter.

b. ?? I left without having talked to at least Peter.

c. ?? I left politics without having been at least a mayor.

- Rescuing by additional DE-operators

(82) a. I would never have left without having talked to at least Peter.

b. No politician leaves politics without having been at least a mayor.

c. Nobody doubts that Mary is at least 20 years old. 
Global PPIs and obligatory exhaustivity

- Rescuing by a factive verb

(83) a. [Context: Speaker and addressee know that Mary is more than 20 years old but don't know her precise age.] John doesn't know that Mary is at least 20 years old.

b. [Context: Speaker and addressee know that Mary met Peter yesterday and don't know whether she met anybody else.] Apart from us, few people know that Mary met at least Peter yesterday.

Now, in the case of at least, an account in terms of obligatory exhaustification does not seem to be available. If anything, in unembedded contexts, what at least does is that it prevents an exhaustivity effect from arising. That is, while a sentence such as John saw Peter, in certain contexts, triggers the inference that John didn't see anybody besides Peter, the sentence John saw at least Peter strongly suggests that the speaker considers it possible that John saw someone besides Peter.

Nevertheless, I will argue that the distribution of at least is related to that of the exhaustivity operator. An interesting generalization (first discussed in Fox 2004) regarding at least is the following:

(84) A sentence $S$ of the form $[s \ldots$ at least $(\phi) \ldots]$ sounds natural only if the sentence $S^{\prime}$ that results from deleting at least in $S$ can give rise to an exhaustivity effect triggered by some material contained in $\phi$.

At first sight, this could just appear to be a complicated way of stating that at least cannot occur in DE-environments (since this seems to be a constraint on $e x h$ ), in which case it would not tell us anything more than the fact that at least is a global PPI. However, it turns out that the generalization in (84) also makes predictions regarding the distribution of at least in upwardentailing (UE) contexts. As was noted by Fox \& Hackl (2007) (see also Fox 2007b, Chierchia, Fox \& Spector 2009, 2012), there are expressions that do not trigger exhaustivity effects when unembedded, unless specific contextual information is present, but do trigger exhaustivity effects in the scope of a necessity modal. Such expressions include modified numerals of the form more than $n$. Now, a prediction of (84) is that at least can take scope over more than $n$ and associate with it (at least is quite clearly a focus-sensitive element) exactly in those contexts and syntactic environments where more than $n$ triggers a scalar inference. 
Benjamin Spector

Let me introduce the relevant facts. Consider (85).

(85) John solved more than five problems.

As an answer to How many problems did John solve yesterday?, (85) does not trigger the inference that John didn't solve more than six problems (in which case it would end up conveying that John solved exactly six problems). In contrast with this, there are contexts where (85) does trigger an upperbounded reading, e.g., contexts in which it is understood that students are categorized into groups based on the number of problems they solved. To make this clear, consider the following:

(86) Context: Grades are attributed on the basis of the number of problems solved. People who solve between one and five problems get a C. People who solve more than five problems but fewer than nine problems get a $B$, and people who solve 9 problems or more get an $A$.

John solved more than five problems. Peter solved more than nine.

In this context, the sentence John solved more than five problems can easily be intepreted as meaning that John solved more than five but fewer than nine, such that he will get a $B$.

Now, the crucial observation (cf. (87) and (88) below) is that in the first case (where the relevant sentence is uttered in a context where we are interested in the precise number of problems that John solved), at least cannot modify more than five, while it can in the second case, as expected given the generalization in (84).

(87) a. How many problems did John solve yesterday?

b. \#John solved at least more than five problems.

(88) Context: Grades are attributed on the basis of the number of problems solved. People who solve between one and five problems get a $C$. People who solve more than five problems but fewer than nine problems get a $B$, and people who solve nine problems or more will get an A.

John solved at least more than five problems. He will therefore get an A or a B.

A second important observation is that while more than $n$ does not trigger a scalar inference when it occurs unembedded, except in contexts such as the one in (86), it does so very easily when embedded under a necessity 
Global PPIs and obligatory exhaustivity

modal. That is, (89) below, uttered as an answer to How many problems is John required to solve, minimally?, implicates that John is not required to solve more than six problems:

(89) John is required to solve more than five problems.

$\rightsquigarrow$ John doesn't have to solve more than six problems.

Now, the generalization in (84) leads us to expect that at least can be inserted in (89) in a position where it scopes over the modal and associates with more than $n$. This prediction is borne out:

(9o) John is at least required to solve more than FIVE problems (I don't know how many exactly).

Note that at least can also be inserted in a position lower than the modal, but where it can presumably be interpreted as taking scope over it:

(91) John is required to solve at least more than FIVE problems (I don't know how many exactly).

In both cases, the interpretation we get is roughly the following: For John, the minimal required number of solved problems is at least five.

While I will not provide an explanation for the generalization in (84), the important point is that this generalization is supported by facts that do not involve the monotonicity of the syntactic environment in which at least occurs, but can help us make sense of the fact that it is a global PPI. Only when a low scalar item $i$ occurs in a syntactic context where it can give rise to a scalar inference can at least be introduced and take scope over $i$. This predicts that at least will not be able to modify expressions that occur in DE-contexts, which goes a long way towards explaining its PPI-like behavior. The question of why this generalization holds is one that I leave for further research. One possible line of investigation is the following. While the semantics of at least is a notoriously difficult problem (see Geurts \& Nouwen 2007, Nouwen 2010, Büring 2008), at least might be viewed as an operator whose main import is that it prevents an exhaustivity effect from arising in its scope. If so, it might be in a sense vacuous (and hence infelicitous) when its prejacent occurs in a position where exhaustification is ruled out by the Economy Constraint. 
Benjamin Spector

\subsection{Approximately}

The modifier approximately seems to behave just like at least in all relevant respects.

(92) Anti-licensing (both short-distance and long-distance)

a. *Mary is not approximately 20 years old.

b. ?? John doubts that Mary is approximately 20 years old.

(93) Rescuing in DE-environments

a. If Mary were not approximately 20 years old, ...

b. Nobody doubts that Mary is approximately 20 years old.

(94) Factive Intervention

a. ?? John is not certain that Mary is approximately 20 years old.

b. John does not know that Mary is approximately 20 years old.

While I will not say anything substantial regarding the meaning of approximately and how it relates to exhaustification, it is worth pointing out that French approximativement (which is the counterpart of approximately) appears to obey the very same generalization as at least, based on a preliminary investigation with a few French speakers. Namely:

(95) A sentence $S$ of the form $[s \ldots$ approximativement $(\phi) \ldots]$ sounds natural only if the sentence $S^{\prime}$ that results from deleting approximativement in $S$ can give rise to an exhaustivity effect triggered by some material contained in $\phi$.

This generalization can be illustrated by the contrast between the two French dialogues in (96) and (97) (I have not tested the English counterparts of these sentences):

(96) a. Combien de problèmes Jean a-t-il résolu ? 'How many problems did Jean solve?'

b. ?? Jean a résolu approximativement plus de dix problèmes (je ne sais pas exactement).

'Jean solved approximately more than ten problems (I don't know exactly).'

(97) a. Combien Jean doit-il résoudre de problèmes au minimum ?

'How many problems does Jean have to solve at the minimum?' 
Global PPIs and obligatory exhaustivity

b. (?) Jean doit approximativement résoudre plus de dix problèmes (je ne sais pas exactement).

'John is approximately required to solve more than ten problems (I don't know exactly).'

While (96b) is very odd, (97b) is relatively acceptable (though not fully natural), under a reading that can be paraphrased as follows:

(98) The minimal number of problems Jean has to solve is approximately 11.

As was the case for at least, the generalization stated in (95) goes a long way towards explaining why the distribution of approximately is that of a global PPI.

\section{$7.3 \quad \ldots$ and yet others}

Before concluding this paper, let me note that the class of global PPIs seems to include a number of other items. Besides items that are close in meaning to approximately, (around, about), all class B modifiers in the sense of Nouwen 2010 seem to be global PPIs (at most, up to, from $X$ to $Y$, etc.). As Nouwen discusses, these items are characterized by the fact that in unembedded contexts, they give rise to obligatory epistemic effects. At least some of these items seem to obey a similar generalization as at least and approximately (cf. (84) and (95)). Consider for instance the following contrast - perceived by 4 out of 4 informants (all linguists) for its French counterpart (both sentences are perceived as quite deviant in an absolute sense):

(99) a. *John solved from more than five to more than ten problems (I don't remember exactly).

b. ?? John has to solve from more than five to more than ten problems (I don't remember exactly).

$\leadsto$ The minimal number of problems John has to solve is between 6 and 11 (I don't remember exactly).

Finally, I should note that the class of global PPIs also includes yet other items, such as, for instance, the adverbs clearly and relatively. 
Benjamin Spector

\section{Conclusion}

I have argued that positive polarity items should be distinguished according to whether their anti-licensing conditions apply locally or globally. For a number of global PPIs (complex disjunctions, almost, French quelques), the relevant anti-licensing condition can be reduced to an independently motivated hypothesis - namely, that they have to occur in the scope of an exhaustivity operator or in positions where they can trigger strengthened presuppositions.

Of course, this proposal raises the question why items such as soit_soit, almost or quelques, rather than others, trigger obligatory exhaustification. The fact that complex disjunctions in many languages behave similarly suggests that this property is not accidental. One can speculate that such items obligatorily activate alternatives, i.e., that they are, in a sense, obligatorily focused (whether or not this is reflected in their prosody). If we assume that alternatives cannot be evoked if they do not make any contribution, we may be in a position to explain why such items prefer to be in the scope of an exhaustivity operator. This is an issue that I leave for further research.

\section{Appendix: Controlled judgments on soit_soit and almost}

\section{A Data on the distribution of soit_soit}

In order to confirm judgments that I had gathered from informants in an informal way, I conducted an on-line survey with 14 French-speaking students and researchers in linguistics or philosophy. I excluded every person whose judgments I had collected before, as well as anyone who had ever attended a talk where this work was presented.

\section{A.1 Predictions to be tested}

The survey aimed to test the following predictions:

- Prediction \#1 — Long-distance anti-licensing for soit_soit but not for ou:

Soit_soit is degraded in the scope of one distant DE-operator compared to non-DE contexts, while ou isn't.

- Prediction \#2 - Short-distance anti-licensing for both soit_soit and ou: 
Global PPIs and obligatory exhaustivity

Both ou and soit_soit are degraded in the immediate scope of negation

- Prediction \#3-Rescuing:

Soit_soit is less degraded in the scope of two distant DE-operators than in the scope of one distant DE-operator, while no similar contrast is expected for ou.

- Prediction \#4-Flip-flop:

Soit_soit is degraded in the scope of three DE-operators compared to when it is in the scope of two DE-operators, and there is no similar contrast for ou.

- Prediction \#5 - Factive intervention:

Soit_soit is more acceptable in the scope of a negated factive verb than in the scope of a negated non-factive attitude verb, and no similar contrast obtains for ou.

\section{A.2 Procedure and material}

I asked for graded judgments, on a scale from 1 to 9 , for sentences that appeared together on the screen in groups of four or six sentences. Participants were explicitly asked to rate each sentence in comparison with all other sentences of the same group. The ordering of sentences within a group was randomized, and the ordering of groups was randomized too, with one exception: two specific groups occurred at the very end (in arbitrary relative order). The reason for this is that these groups tested for the most complicated cases, and this constraint was meant to ensure that subjects would be well trained when evaluating these cases. Each sentence can be characterized in terms of a) which disjunction appeared in it, and b) what kind of environment the disjunction appeared in. In each group, apart from the factors being manipulated, the sentences were similar to each other (same or similar lexical items, same constructions). Each group tested a certain set of environments, always with both ou and soit_soit. A group can thus be characterized in terms of the environments it tested. Here is a compact description of all the groups (see Section A.6 for an exhaustive description). ${ }^{41}$

41 Groups $6 \mathrm{~A}$ and $6 \mathrm{~B}$ are those that always appeared after all others. 
Benjamin Spector

\begin{tabular}{ll} 
Groups & Environments \\
\hline 1A, 1B & No negation, Clause-mate negation, Distant negation \\
\hline 2A, 2B, 2C, 2D & o DE-operators, 1 distant DE-operator \\
\hline 3 & o DE-operators, 1 distant DE-operator, 2 distant DE-operators \\
\hline 4 & 1 distant DE-operator, 2 distant DE-operators \\
\hline $5 \mathrm{~A}, 5 \mathrm{~B}$ & Negated non-factive attitude verb, Negated factive verb \\
\hline $6 \mathrm{~A}, 6 \mathrm{~B}$ & 1 DE-operator, 2 DE-operators, 3 DE-operators \\
\hline
\end{tabular}

\section{A.3 Data treatment}

The comparisons I will report always involve four conditions, all instantiated within the same groups, defined by two factors: Disjunction Type (ou vs. soit) and Environment (e.g., 1 DE distant operator vs. no DE operator).

We are interested in a) contrasts between two conditions (e.g., contrast between soit_soit in $1 \mathrm{DE}$-environments vs. in $o \mathrm{DE}$-environments), and b) interactions between factors (e.g., we want to know whether any contrast that may exist for ou in $1 D E$ vs. $O D E$-environments is marginal compared to the contrast found with soit_soit).

To test for contrasts between two conditions, I compute, for each subject, the median value across groups of the difference between the ratings given by this subject to the two relevant conditions (i.e., score for the sentence that I predict to be the more acceptable - score for the sentence that I predict to be less acceptable). I then test by means of a Wilcoxon signed-rank test ${ }^{42}$ whether these median values are significantly higher than o.

To test for interactions between factors, given that the conditions for using a parametric test such as a 2-way ANOVA are not necessarily met, I test the difference between differences within each pair of conditions. That is, for each subject $s$, I compute the median value across groups of $(X 1(s)-$ $Y 1(s))-(X 2(s)-Y 2(s))$, where $X$ and $Y$ correspond to the two levels of the first factor, and 1 and 2 to the two levels of the second factor, $X 1(s)$ is the rating that subject $s$ assigned to condition $X 1$. I then test by means of a Wilcoxon signed-rank test whether these median values are significantly

42 I report the results of Wilcoxon signed-rank tests in terms of the $V$-statistics, the sum of all positive ranks. The more standard $W$, i.e., the difference between positive and negative ranks, is uniquely determined by $V$, the sample size and the number of ties. 
Global PPIs and obligatory exhaustivity

higher than o. If so, I conclude that there is a significant interaction, i.e., that the difference between $X 1$ and $Y 1$ is greater than between $X 2$ and $Y 2$.

The $p$-values I report are always two-tailed. The aggregate value for a given score is always the median value of the median values obtained for each subject.

\section{A.4 Results}

\section{A.4.1 Prediction \# 1 - Long-distance anti-licensing}

To test for Prediction \#1, let us consider all groups $(1 \mathrm{~A}, 1 \mathrm{~B}, 2 \mathrm{~A}, 2 \mathrm{~B}, 2 \mathrm{C}, 2 \mathrm{D}, 3)$ which instantianted (at least) the four conditions defined by the following factors: Disjunction Type and Environment - 1 distant DE-operator vs. no DE-operator. ${ }^{43}$

Looking at all such groups, we find: a) that soit_soit is degraded in the scope of exactly $1 \mathrm{DE}$ distant operator as opposed to when it is not in a negative context ( 3 vs. $8, V=105,{ }^{44} p<.0005$ ), and b) that whatever comparable contrast there may be for ou (8.25 vs. 8.5) is either in the opposite direction or marginal compared with the one found with soit (Difference in differences: $V=105, p<.0005) .{ }^{45}$

\section{A.4.2 Prediction \#2 - Short-distance anti-licensing}

Two groups (1A, 1B) were designed in part to test Prediction \#2. They each consisted of 6 sentences, defined by two factors: Disjunction Type and Environment - close negation, distant negation, no negation. ${ }^{46}$

As predicted, ou is degraded in the immediate scope of negation vs. in a positive context (4.5 vs. $8, V=83.5, p<.005$ ). Furthermore, it is not

43 Some of these groups also instantiated two additional conditions: ou vs. soit_soit in a positive environment. Cf. Section A.6.

44 A value of $V=105$ means that every single subject reported a contrast (i.e., all ranks are positive, so $V=1+2+\ldots+14=105$ ). The associated $p$-value is then as low as is mathematically possible given the sample size.

45 These groups included cases where the DE-operator is a DE quantifier such as fewer than ten students, which I classified as a long-distance case. If we further divide these groups into two subtypes, i.e., those that involved a DE-quantifier in subject position and those that involved a DE-operator separated from the soit_soit or ou by a clause boundary, we find exactly the same pattern for each subtype.

46 Distant negation includes cases where the relevant disjunction is in the scope of a negative attitude verb. 
similarly degraded when in the scope of a distant negation. Specifically, whatever contrast there may be between the distant negation context (8.25) and the no negation context (8) for $o u$, this contrast is either in the opposite direction or marginal compared to the corresponding contrast for soit_soit in the very same groups (Difference in differences: $V=105, p<.0005$ ). As expected, compared to positive environments, soit_soit is degraded both in the immediate scope of negation ( 2 vs. 8.25, $V=105, p<.0005$ ) and in the scope of a distant DE-operator (3.75 vs. 8.25, $V=105, p<.0005$ ).

\section{A.4.3 Prediction \#3 - Rescuing (1 vs. 2 DE-operators)}

To test for Prediction \#3, i.e., that soit_soit is subject to rescuing, let us consider all groups that included both sentences with one DE-operator and sentences with two DE-operators (groups 3, 4, 6A, 6B).47 I thus focus on four conditions, defined by the following two factors: Disjunction Type and Environment -1 vs. 2 DE-operators.

First, soit_soit is, as expected, significantly more acceptable under the scope of two DE-operators than under the scope of one DE-operator (7.75 vs 3.75, $V=101, p<.001)$. Second, there is no comparable contrast between 2 DE-environments (8.75) and 1 DE-environments (9) in the case of ou (Difference in differences: $V=105, p<.0005)$.

\section{A.4.4 Prediction \#4-Flip-flop (1 vs. 2 vs. 3 DE-operators)}

Two groups (6A, 6B) included six sentences based on the following factors: Disjunction Type and Environment-1, 2 or 3 DE-operators. As expected, in these groups, soit_soit is significantly degraded when in the scope of three DE-operators compared to the case where it is in the scope of two DE-operators ( 5 vs. $8, V=91, p<.0005$ ). There is no similar contrast for ou between $2 \mathrm{DE}$ (7.75) and $3 \mathrm{DE}$ (7.50) environments (Difference in differences: $V=91, p<.0005)$. As expected, in these groups, soit is also worse in the scope of one DE-operator than in the scope of two DE-operators (4.75 vs. 8,

47 Again, these groups include groups that instantiated more than just these conditions, but also conditions with no DE-operators. Cf. Section A.6. 
Global PPIs and obligatory exhaustivity

$V=96, p<.005)$. There is no similar contrast for ou between 2 DE (7.75) and 1 DE (9) environments (Difference in differences: $V=105, p<.0005$ ). ${ }^{48}$

\section{A.4.5 Prediction \#5 - Factive intervention}

Two groups (5a, 5b) tested the contrast between neg+know that and neg+believe/ think that, i.e., tested specifically for factive intervention. As predicted, when soit_soit occurs in the scope of a negated factive verb, it is significantly more acceptable than in the scope of a negative non-factive attitude verb (7.25 vs. $3.50, V=105, p<.0005)$. In the case of $o u$, there is no similar contrast (7.50 vs. 7.75 , Difference in differences: $V=92.5, p<.01$ ).

\section{A.5 Conclusion}

The results of this survey support all the generalizations made in the paper regarding the distribution of soit_soit. Namely, soit_soit is degraded when it occurs in a globally DE-environment, while ou is degraded only in the scope of a clause-mate negation. Furthermore, soit_soit is significantly more acceptable in the scope of a negated factive verb than in the scope of a negated non-factive verb (factive intervention).

\section{A.6 Detailed description of the survey}

Here is a compact description of the survey. ${ }^{49}$

- Group \#1A - Environments: no negation, close negation, distant negation - 6 sentences

Marie [a]/[n' a pas] invité [Léa ou Jean]/[soit Marie soit Paul] à dîner.

Je ne pense pas que Marie ait invité [Pierre ou Julie]/[soit Anne soit Paul] à dîner.

- Group \#1B - Idem

48 If anything, there is a contrast in the opposite direction, i.e., ou in these groups is slightly more acceptable in 1 DE-environments than in 2 DE-environments, though this contrast is only marginally significant $(\mathrm{V}=25, \mathrm{p}=.078)$.

49 Within the same groups, I didn't always keep constant the proper names or nouns occurring in a sentence, but the nouns used within a group always belonged to the same semantic class (e.g., names of fruit). The schematic description I use here ignores some of these slight variations. 
Marie [a]/[n' a pas] mangé [les pommes ou les bananes]/[soit les pommes soit les bananes].

Je doute que Nicolas ait mangé [les poires ou les oranges]/[soit les pommes soit les bananes].

- Group \#2A - Environments: o vs. 1 distant DE-operator - 4 sentences

Il est [probable]/[peu probable] que le fugitif ait fui [en Allemagne ou en Italie]/[soit en Allemagne soit en Italie].

- Group \#2B - Idem

[Certains étudiants]/[Aucun étudiant] [parlent]/[ne parle] [russe ou italien]/[soit espagnol soit anglais].

- Group \#2C - Idem

Beaucoup/peu de français connaissent [l'italien ou le russe]/[soit l'anglais soit le russe].

- Group \#2D - Idem

Parmi mes étudiants, [plus de dix]/[moins de dix] parlent [espagnol ou italien]/[soit italien soit allemand].

- Group \#3-Environments: o, 1 or 2 distant DE-operators - 6 sentences Je pense/doute qu'il serait utile que Jacques apprenne [l'italien ou l'espagnol]/ [soit le russe soit l'italien].

Personne ne doute qu'il serait utile que Jacques apprenne [l'allemand ou l'anglais]/[soit l'anglais soit l'espagnol].

- Group \#4-Environments: 1 or 2 distant DE-operators - 4 sentences

[J'ai emmené]/[Je n'emmène jamais] Marie au cinéma sans qu'elle ait demandé la permission [à son père ou à sa mère]/[soit à son père soit à sa mère].

- Group \#5A - Environments: negated non-factive attitude verb, negated factive verb -4 sentences

Marie a dit à ses parents qu'elle désire faire des études scientifiques, mais ils ne croient/savent pas qu'elle prévoie/prévoit de s'inscrire [en médecine ou en biologie]/[soit en médecine soit en biologie].

- $\quad$ Group \#5B - Idem

Bien que Jean soit un étudiant brillant, Anne ne croit pas qu'il étudiera [à Yale ou à Princeton]/[soit à Yale soit à Princeton].

Bien qu'elle soit très informée, Marie ne sait pas que Paul étudiera [à Yale ou à Princeton]/[soit à Yale soit à Princeton]. 
Global PPIs and obligatory exhaustivity

The following two groups always appeared after all others.

- Group \#6A - Environments: 1, 2 or 3 DE-operators - 6 sentences

Je trouve inimaginable d'habiter [à Paris ou à New-York]/[soit à Paris soit à New-York].

Je trouve inimaginable de ne pas habiter [à Paris ou à New-York]/[soit à

Paris soit à New-York].

Je trouve ne trouve pas inimaginable de ne pas habiter [à Paris ou à NewYork]/[soit à Paris soit à New-York].

- Group \#6B - idem

Je trouverais inadmissible que tu votes [pour Sarkozy ou pour Hollande]/[soit pour Sarkozy soit pour Hollande].

Je trouverais inadmissible que tu ne votes pas [pour Sarkozy ou pour Hollande]/[soit pour Sarkozy soit pour Hollande].

Je ne trouverais pas inadmissible que tu ne votes pas [pour Sarkozy ou pour Hollande]/[soit pour Sarkozy soit pour Hollande].

\section{B Data on the distribution of almost}

I ran a survey on-line on the distribution of almost, with 42 native English speakers, recruited through the Amazon Mechanical Turk platform. The general procedure was exactly the same as with the survey on soit_soit. I also applied the same type of data treatment. I systematically contrasted almost with a control-item. For instance, almost all in a certain environment was compared with all in the same environment, or almost having full nuclear capacity was compared with being close to having full nuclear capacity in the same environment.

\section{B.1 Predictions to be tested}

The survey aimed to test the following predictions:

- Prediction \#1 - Anti-licensing:

Almost is degraded in the scope of one DE-operator, compared to the control item, both if the DE-operator is a clause-mate negation and if it is a distant negation or some other type of DE-operator. 
- Prediction \#2 - Rescuing:

Almost is less degraded in the scope of two distant DE-operators than in the scope of one distant DE-operator (rescuing), while no similar contrast is expected for the control item.

- Prediction \#3 - Factive intervention:

Almost is more acceptable in the scope of a negated factive verb than in the scope of a negated non-factive attitude verb (or a negative non-factive attitude verb), and no similar contrast obtains for control items.

\section{B.2 Material}

The survey started with a group of six sentences that served as training items and were otherwise not relevant. After this first group, sentences appeared together in groups of four sentences. In each group, two types of environments where tested, and both almost and the control item were tested in each environment. The ordering of groups, and of sentences within each group, was randomized. Here is a compact description of the groups, based on the type of environments they tested (see Section B.5 for an exhaustive description).

\begin{tabular}{ll} 
Groups & Environments \\
\hline $1 \mathrm{~A}, 1 \mathrm{~B}, 1 \mathrm{C}$ & No negation, Clause-mate negation \\
\hline $2 \mathrm{~A}, 2 \mathrm{~B}, 2 \mathrm{C}, 2 \mathrm{D}, 2 \mathrm{E}$ & o DE-operators, 1 distant DE-operator \\
\hline 3 & 1 distant DE-operator, 2 distant DE-operators \\
\hline $4 \mathrm{~A}, 4 \mathrm{~B}$ & Negated non-factive attitude verb, Negated factive verb \\
\hline
\end{tabular}

\section{B.3 Results}

\section{B.3.1 Prediction \# 1 - Anti-licensing}

- $\quad$ Main result

Across all groups which tested both positive environments and DE environments $(1 \mathrm{~A}, 1 \mathrm{~B}, 1 \mathrm{C}, 2 \mathrm{~A}, 2 \mathrm{~B}, 2 \mathrm{C}, 2 \mathrm{D}, 2 \mathrm{E})$, almost is, as predicted, degraded in DE environments compared to positive environments (4 vs. 8, 
Global PPIs and obligatory exhaustivity

$\left.V=820, p<10^{-11}\right)$. Whatever contrast there may be for control items between positive and negative environments ( 8 vs. 9$)$ is marginal compared to what is found for almost (Difference in differences: $V=741, p<10^{-11}$ ).

- More fine-grained results

We observe the same pattern by treating separately groups in which the DE-operator was a clause-mate negation $(1 \mathrm{~A}, 1 \mathrm{~B}, 1 \mathrm{C})$ and groups where the DE-operator was more distant $(2 \mathrm{~A}, 2 \mathrm{~B}, 2 \mathrm{C}, 2 \mathrm{D}, 2 \mathrm{E})$.

That is, almost is degraded in the immediate scope of negation compared to cases where the negation is removed (3.5 vs. 8.25, $V=903, p<10^{-11}$ ), and whatever contrast there may be for control items (9 vs. 8.5) is marginal compared to what is found for almost (Difference in differences: $V=861, p<$ $10^{-12}$ )

Likewise, almost is also degraded when in the scope of a distant DEoperator compared to cases (in the same groups) where it occurs in a positive environment ( 5 vs. $8, V=591, p<10^{-9}$ ). Whatever contrast there may be for control items (9 vs. 8.5) is marginal compared to what is found for almost (Difference in differences: $V=485, p<10^{-7}$ ). ${ }^{50}$

\section{B.3.2 Prediction \#2 - Rescuing}

The only group that tested for rescuing was Group \#3. In this group, as predicted, almost is degraded in the scope of one DE operator compared to when it occurs in the scope of two DE operators, even though the size of the observed effect is small (3 vs. $4, V=288, p<.05$ ). Whatever contrast there may be for control items ( 7 vs. 7 ) is marginal compared with the one found with almost (Difference in differences: $V=376.5, p<.05$ ).

\section{B.3.3 Prediction \#3 - Factive intervention}

Groups $4 \mathrm{~A}$ and $4 \mathrm{~B}$ tested for factive intervention. They contrasted almost and a control item in the scope of a) a negated non-factive attitude verb (believe) and b) a negated factive verb (know).

As predicted, almost is degraded in the scope of a negated non-factive verb compared to when it is in the scope of a negated factive verb (4.75 vs. 6 ,

50 If we further distinguish between groups in which the DE-operator is a DE-quantifier in subject position and those in which it is separated from the almost or the control item by a clause boundary, we find exactly the same general pattern for both cases. 
$V=605, p<0.0005)$. Furthermore, there is no similar contrast for control items (Difference in differences: $V=660, p<10^{-6}$ ). In fact, there is a contrast in the opposite direction, with the control item receiving a higher score in the scope of a negated non-factive verb than in the scope of a negated factive verb ( 8 vs. $6.25, V=408.5, p<.0005) .{ }^{51}$

\section{B.4 Conclusion}

The results of the survey on almost confirm the main empirical generalizations of the paper regarding its distribution: almost is, all else being equal, significantly more acceptable when it occurs in a globally UE environment than in a DE environment. It thus qualifies as a global PPI. When under the scope of a negated attitude verb, almost is significantly more acceptable if the verb is factive (factive intervention).

\section{B.5 Detailed description of the survey}

- Training group Mary ate/didn't eat some of the rice at dinner. Mary has/hasn't already been in Rome. Mary has/hasn't often been in Rome.

- Group \#1A - Environments: No negation, clause-mate negation Mary [solved]/[didn't solve] [all]/[almost all] of the problems on time.

- Group \#1B - Idem Sue [ate]/[didn't eat] [all]/[almost all] of the rice at dinner.

- $\quad$ Group \#1C - Idem

This country is/isn't close to having full nuclear capacity. This country [almost has]/[doesn't almost have] full nuclear capacity.

- Group \#2A - Environments: o DE-operators, 1 distant DE-operator I [think]/[don't think] that Mary solved [all]/[almost all] of the problems on time.

- Group \#2B - Idem

I [believe]/[doubt] that Sue ate [all]/[almost all] of the rice at dinner.

- Group \#2C - Idem

This country [is]/[is not] believed [to be close to having full]/[to have almost full nuclear capacity.

51 This last comparison was not initially planned. 
Global PPIs and obligatory exhaustivity

- Group \#2D - Idem

[Some]/[No] students did [all]/[almost all] of the homework before the deadline.

- Group \#2E - Idem

[Many]/[Few] countries [are close to having full]/[almost have full] nuclear capacity.

- Group \#3-Environments: 1 or 2 distant DE-operators

I left the party without having told [all]/[almost all] of the guests that I was leaving.

I never leave a party without having told [all]/[almost all] of the guests that I was leaving.

- Group \#4A - Environments: negated non-factive attitude verb, negated factive verb

Lisa informed her parents that she did very well at the exam, but they don't $[$ think $] /[k n o w]$ that she solved [all]/[almost all] of the problems.

- Group \#4B - Idem

Even though John is a very bright student, Ann doesn't think that he will be admitted to [all]/[almost all] of the universities he applied for.

Even though Sue is very well informed, she doesn't know that Peter was admitted to [all]/[almost all] of the universities he applied for.

\section{References}

Büring, Daniel. 2008. The least at least can do. West Coast Conference on Formal Linguistics (WCCFL) 26. 114-120. http://www.lingref.com/cpp/ wccfl/26/paper1662.pdf.

Carston, Robin. 1996. Metalinguistic negation and echoic use. Journal of Pragmatics 25(3). 309-330. http://dx.doi.org/10.1016/o378-2166(94) oolog-X.

Chemla, Emmanuel. 2008. An epistemic step for antipresuppositions. Journal of Semantics 25(2). 141-173. http://dx.doi.org/10.1093/jos/ffmo17.

Chemla, Emmanuel \& Benjamin Spector. 2011. Experimental evidence for embedded scalar implicatures. Journal of Semantics 28(3). 359-400. http: //dx.doi.org/10.1093/jos/ffq023.

Chierchia, Gennaro. 2006. Broaden your views: Implicatures of domain widening and the "logicality" of language. Linguistic Inquiry 37. 535-590. http: //dx.doi.org/10.1162/ling.2006.37.4.535. 
Benjamin Spector

Chierchia, Gennaro, Stephen Crain, Maria Teresa Guasti, Andrea Gualmini \& Luisa Meroni. 2001. The acquisition of disjunction: Evidence for a grammatical view of scalar implicatures. Boston University Conference on Language Development (BUCLD) 25. 157-168. http://www.researchgate.net/ publication/232520871_The_Acquisition_of_Disjunction_Evidence_for_ a_Grammatical_View_of_Scalar_Implicatures/file/9fcfd513f948630158. pdf.

Chierchia, Gennaro, Danny Fox \& Benjamin Spector. 2009. Hurford's constraint and the theory of scalar implicatures. In Paul Egré \& Giorgio Magri (eds.), Presuppositions and implicatures - Proceedings of the MIT-Paris workshop, 47-62. Cambridge, MA: MIT Working Papers in Linguistics (MITWPL). http://semanticsarchive.net/Archive/mE2OGIzY/HCChierchiaFoxSpector. pdf.

Chierchia, Gennaro, Danny Fox \& Benjamin Spector. 2012. Scalar implicature as a grammatical phenomenon. In Claudia Maienborn, Paul Portner \& Klaus von Heusinger (eds.), Semantics: An international handbook of natural language meaning, vol. 3, 2297-2331. Berlin \& Boston: de Gruyter. http: //dx.doi.org/10.1515/9783110253382.2297.

Crain, Stephen. 2008. The interpretation of disjunction in Universal Grammar. Language \& Speech 51. 151-169. http://dx.doi.org/10.1177/ o0238309080510010901.

Crnič, Luka. 2013. Focus particles and embedded exhaustification. Journal of Semantics 30(4). 533-558. http://dx.doi.org/10.1093/jos/ffso18.

Fauconnier, Gilles. 1975. Pragmatic scales and logical structure. Linguistic Inquiry 6(3). 353-375. http://www.jstor.org/stable/4177882.

von Fintel, Kai. 1999. NPI licensing, Strawson entailment, and context dependency. Journal of Semantics 16(2). 97-148. http://dx.doi.org/10.1093/jos/ 16.2.97.

Fox, Danny. 2004. Only a little bit more. Handout for a class taught at USC. http://web.mit.edu/linguistics/people/faculty/fox/class_5.pdf.

Fox, Danny. 2007a. Free choice and the theory of scalar implicatures. In Penka Stateva \& Uli Sauerland (eds.), Presupposition and implicature in compositional semantics, 537-586. New York, NY: Palgrave-Macmillan.

Fox, Danny. 2007b. Too many alternatives: Density, symmetry, and other predicaments. Semantics and Linguistic Theory (SALT) 17. 89-111. http: //elanguage.net/journals/index.php/salt/article/viewFile/17.89/1844. 
Global PPIs and obligatory exhaustivity

Fox, Danny. 2014. Cancelling the maxim of quantity: Another challenge for a Gricean theory of scalar implicatures. Semantics and Pragmatics 7(5). 1-20. http://dx.doi.org/10.3765/sp.7.5.

Fox, Danny \& Martin Hackl. 2007. The universal density of measurement. Linguistics and Philosophy 29. 537-586. http://dx.doi.org/10.1007/s10988oo6-9004-4.

Fox, Danny \& Benjamin Spector. 2008. Economy and embedded exhaustification. Hand-out. http://lumiere.ens.fr/ bspector/Webpage/Fox_Spector_ EE.pdf.

Gajewski, Jon R. 2002. On analyticity in natural language. Ms., MIT. http: //www.gajewski.uconn.edu/papers/analytic.pdf.

Gajewski, Jon R. 2008. NPI any and connected exceptive phrases. Natural Language Semantics 16(1). 69-110. http://dx.doi.org/10.1007/s11050-0079025-8.

Gajewski, Jon R. \& Yael Sharvit. 2012. In defense of the grammatical approach to local implicatures. Natural Language Semantics 20(1). 31-57. http: //dx.doi.org/10.1007/s11050-011-9074-x.

Geurts, Bart \& Rick Nouwen. 2007. At least et al: The semantics of scalar modifiers. Language 83(3). 533-559. http://dx.doi.org/10.1353/lan.2007. 0115 .

Geurts, Bart \& Bob van Tiel. 2013. Embedded scalars. Semantics and Pragmatics 6(9). 1-37. http://dx.doi.org/10.3765/sp.6.9.

Heim, Irene. 1991. Artikel und Definitheit. In Arnim von Stechow \& Dieter Wunderlich (eds.), Semantik: Ein internationales Handbuch der zeitgenössischen Forschung, 487-535. Berlin: de Gruyter.

Heim, Irene. 2000. Degree operators and scope. Semantics and Linguistic Theory (SALT) 10. 40-64.

Homer, Vincent. to appear. Domains of polarity items. Journal of Semantics. http://semanticsarchive.net/Archive/DlmZmMiY/domains.pdf.

Horn, Laurence R. 1972. On the semantics of logical operators in English. Yale University $\mathrm{PhD}$ thesis.

Horn, Laurence R. 1985. Metalinguistic negation and pragmatic ambiguity. Language 61(1). 121-174. http://dx.doi.org/10.2307/413423.

Horn, Laurence R. 1989. A natural history of negation. Chicago: University of Chicago Press.

Jayez, Jacques \& Lucia Tovena. 2008. Presque and almost: How argumentation derives from comparative meaning. Empirical Issues in Syntax and Semantics (CSSP) 7. 1-23. http://www.cssp.cnrs.fr/eiss7/jayez-tovena-eiss7.pdf. 
Benjamin Spector

Jespersen, Otto. 1909-1949. A modern English grammar on historical principles. London: Allen \& Unwin.

Kennedy, Chris. 2007. Vagueness and grammar: The semantics of relative and absolute gradable adjectives. Linguistics and Philosophy 3o(1). 1-45. http://dx.doi.org/10.1007/s10988-006-9008-o.

Levinson, Stephen C. 2000. Presumptive meanings: The theory of generalized conversational implicature. Cambridge, MA: MIT Press.

Mouret, François. 2007. Grammaire des constructions coordonnées. Coordinations simples et coordinations à redoublement en français contemporain. Université Paris $7 \mathrm{PhD}$ thesis.

Nicolae, Andreea. 2012. Positive polarity items: An alternative-based account. Sinn und Bedeutung 16(2). 475-488. http://people.fas.harvard.edu/ nicolae/Andreea_Nicolae/Papers_files /Nicolae\% 20-\%20PPIs\% $20 S u B$. 2012\%2ofinal.pdf.

Nouwen, Rick. 2006. Remarks on the polar orientation of almost. Linguistics in the Netherlands 23(1). 162-173. ISSN: 0929-7332. http://dx.doi.org/10. 1075/avt.23.17nou.

Nouwen, Rick. 2010. Two kinds of modified numerals. Semantics and Pragmatics 3(3). 1-41. ISSN: 1937-8912. http://dx.doi.org/10.3765/sp.3.3.

Penka, Doris. 2006. Almost there: The meaning of almost. Sinn und Bedeutung 10. 275-286. http://www.sfs.uni-tuebingen.de/ cebert/papers / SuBıoProceedings.pdf.

Percus, Orin. 2006. Antipresuppositions. In Ayumi Ueyama (ed.), Theoretical and empirical studies of reference and anaphora: Toward the establishment of Generative Grammar as an empirical science, 52-73. Japan Society for the Promotion of Science.

van Rooij, Robert \& Katrin Schulz. 2004. Exhaustive interpretation of complex sentences. Journal of Logic, Language and Information 13(4). 491-519. http://dx.doi.org/10.1007/s10849-004-2118-6.

Rotstein, Carmen \& Yoad Winter. 2004. Total adjectives vs. partial adjectives: Scale structure and higher-order modifiers. Natural Language Semantics 12(3). 259-288. http://dx.doi.org/10.1023/b:nals.ooooo34517.56898.9a.

Ruyer, Bernard. 1994. Logique. Paris: Presses Universitaires de France.

Sadock, Jerry. 1981. Almost. In Peter Cole (ed.), Radical pragmatics, 281-297. New York, NY: Academic Press.

Sauerland, Uli. 2004. Scalar implicatures in complex sentences. Linguistics and Philosophy 27(3). 367-391. http://dx.doi.org/10.1023/b:ling.0000023378. 71748.db. 
Global PPIs and obligatory exhaustivity

Sauerland, Uli. 2008. Implicated presuppositions. In Anita Steube (ed.), The discourse potential of underspecified structures, vol. 8 (Language, Context and Cognition), 581-6oo. Berlin: Mouton de Gruyter.

Schulz, Katrin \& Robert van Rooij. 2006. Pragmatic meaning and non-monotonic reasoning: The case of exhaustive interpretation. Linguistics and Philosophy 29(2). 205-250. http://dx.doi.org/10.1007/s10988-005-3760-4.

Singh, Raj. 2011. Maximize Presupposition! and local contexts. Natural Language Semantics 19(2). 149-168. http://dx.doi.org/10.1007/s11050-0109066-2.

Spector, Benjamin. 2003. Scalar implicatures: Exhaustivity and Gricean reasoning. European Summer School in Logic, Language and Information (ESSLLI), Student Session 8. Revised version in Spector 2007, 277-288.

Spector, Benjamin. 2007. Scalar implicatures: Exhaustivity and Gricean reasoning. In Maria Aloni, Paul Dekker \& Alastair Butler (eds.), Questions in dynamic semantics, vol. 17 (Current Research in the Semantics/Pragmatics Interface), 225-249. Elsevier. http://dx.doi.org/10.1163/9780080470993\ -O11.

Szabolcsi, Anna. 2002. Hungarian disjunctions and positive polarity. In István Kenesei \& Péter Siptár (eds.), Approaches to hungarian, vol. 8, 217-241. Budapest: Akademiai Kiado.

Szabolcsi, Anna. 2004. Positive polarity-negative polarity. Natural Language and Linguistic Theory 22(2). 409-452. http://dx.doi.org/10.1023/b: nala.0000015791.00288.43.

van der Wouden, Ton. 1997. Negative contexts: Collocation, polarity and multiple negation. London \& New York, NY: Routledge.

Zamparelli, Roberto. 2000. Distributive conjunction and sentence reduction. Ms., Università di Bergamo. http://www.academia.edu/1085162/ Distributive_Conjunction_and_Sentence_Reduction.

Zwarts, Frans. 1998. Three types of polarity. In Fritz Hamm \& Erhard Hinrichs (eds.), Plurality and quantification, 177-238. Dordrecht: Kluwer.

Benjamin Spector

École Normale Supérieure

Institut Jean Nicod

29 rue d'Ulm

Pavillon Jardin

75005 Paris, France

benjamin.spector@ens.fr 